



NBSIR 74-375

\section{REFRIGERATION FOR AN 8 K TO 14 K SUPERCONDUCTING TRANSMISSION LINE}

David E. Daney

Cryogenics Division

Institute for Basic Standards

National Bureau of Standards

Boulder, Colorado 80302

OCTOBER, 1974

Prepared for:

Stanford University

820 Quarry Road

Palo Alto, California 94304 



\section{NBSIR 74-375}

\section{REFRIGERATION FOR AN 8 K TO 14 K SUPERCONDUCTING TRANSMISSION LINE}

David E. Daney

Cryogenics Division

Institute for Basic Standards

National Bureau of Standards

Boulder, Colorado 80302

OCTOBER, 1974

Prepared for:

Stanford University

820 Quarry Road

Palo Alto, California 94304

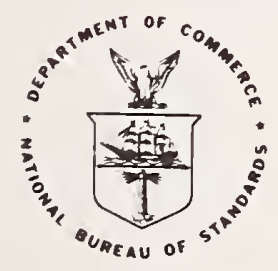

U.S. DEPARTMENT OF COMMERCE, Frederick B. Dent, Secretary 

CONTENTS

Page

1. INTRODUCTION . . . . . . . . . . . . . . . . 1

2. REFRIGERATION ANALYSIS - LOW TEMPERATURE

END . . . . . . . . . . . . . . . . . . . . 3

2. 1 Heat Exchanger Analysis . . . . . . . . . 7

2. 2 Brayton Cycle with Expander Before the Load, Scheme 1.................... 9

2. 3 Brayton Cycle with Expander After the Load, Scheme 2..................... 10

2. 4 Brayton Cycle with a Separate Supercritical

Helium Loop and Circulating Pump ........ 11

2. 5 Comments on the Computations . . . . . . 12

3. REFRIGERATION ANALYSIS - HIGH TEMPERATURE END ....................... . . . . . 13

4. COLD END RESULTS .................... 17

5. DISCUSSION . . . . . . . . . . . . . . . 4 41

6. COST ESTIMATES ..................... 45

6.1 Capital Costs ................ . . . 45

6.2 Optimum Refrigerator Spacing . . . . . . . 48

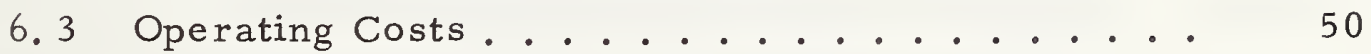

7. ACKNOWLEDGMENTS . . . . . . . . . . 53

8. NOMENCLATURE ....................... 54

9. REFERENCES ..................... 56 


\section{LIST OF FIGURES}

Page

Figure 2.1 Three schemes of refrigeration using supercritical helium. . . . . . . . . . 4

Figure 2.2 One candidate refrigerator using scheme 1 at the cold end . . . . . . . . . . . 5

Figure 2.3 Specific heat of helium as a function of temperature for several pressures. . . . . 6

Figure 3.1 Three possible warm end arrangements . . . 15 Figure 4. 1 through 4.25 - Refrigerator Performance Curves $8 \mathrm{~K}$ Load Exit Temperature . . . . . . . 19

$10 \mathrm{~K}$ Load Exit Temperature . . . . . . . 22

$12 \mathrm{~K}$ Load Exit Temperature . . . . . . 33

$14 \mathrm{~K}$ Load Exit Temperature . . . . . . 37

Figure 6.1 Minimum installed refrigerator cost $/ \mathrm{km}$ for a $10 \mathrm{~km}$ refrigerator spacing (excluding site and site development costs). . . . . . . . . 46

Figure 6.2 Annual refrigeration cost based on table 6.2.

\section{LIST OF TABLES}

Table 6.1 Optimum refrigerator performance for $\mathrm{AU} / \stackrel{\circ}{\mathrm{m}}=1100$ and $\eta_{\mathrm{e}}=0.7 . . . .44$

Table 6.2 Assumed operating cost per refrigerator . . . 52 
REFRIGERATION FOR

AN $8 \mathrm{~K}$ TO $14 \mathrm{~K}$ SUPERCONDUCTING TRANSMISSION LINE David E. Daney

1. INTRODUCTION

This study was sponsored by the Stanford University Hansen Laboratories in support of their superconducting transmission line project. The Stanford investigation focuses on low-loss $\mathrm{Nb}_{3} \mathrm{Sn}$ as the superconductor, and consequently the temperature range of interest is about 8 to $14 \mathrm{~K}$. Because supercritical helium is the only practical refrigerant available in this temperature range, this report investigates its use as a refrigerant for temperatures from 8 to $14 \mathrm{~K}$ and for pressures from 3 to $20 \mathrm{~atm}$.

A number of variables and problems must be considered in optimizing the transmission line coolant passage configuration and size. However, in this report we restrict ourselves to one question-what is the cost of refrigeration for a superconducting transmission line for a specific set of conditions in the line and for a particular refrigerator configuration? Although refrigerator cost correlations such as Strobridge's [1,2] are quite useful for general estimating purposes, these studies do not differentiate between various refrigeration schemes or sets of conditions in the transmission line. They simply give average values for existing refrigerators. If we wish to compare the costs of various arrangements for cooling a transmission line, and of various line pressures, temperatures, and pressure drops, then a more detailed analysis is required.

In making a comparison of the efficiencies of various methods of refrigeration, one must be careful to make realistic and fair comparisons by holding the efficiencies of components such as heat exchangers 
and expanders constant in the comparison. Unfortunately, this has not always been the case with some of the work in the literature, and much confusion as to which schemes are preferred has resulted.

Considering all of the various combinations of expanders, heat exchangers, temperature levels, and pressure levels, there is a myriad of schemes for producing refrigeration with supercritical helium. To reduce the problem of refrigeration analysis to manageable proportions, we have chosen to divide the refrigerator into two parts: a low temperature end (below $30 \mathrm{~K}$ ) where most of the irreversibilities occur, and a high temperature end ( $30 \mathrm{~K}$ to $300 \mathrm{~K}$ ) where helium behaves nearly as an ideal gas, and where the irreversibilities are only a fraction of those at the cold end. The advantages of this approach are clarity of comparison, reduced computation time, and greater generality.

For the low temperature end, we make detailed calculations for three refrigerator arrangements and for a number of combinations of temperature, pressure, and pressure drop in the transmission line. The major effort of this study addresses this low temperature end.

For the high temperature end, we made an estimate of the irreversibilities which depend only on the flow rate. The total work required is then the sum of work required to run the cold end and the warm end.

Finally, based on the first two parts, estimates of refrigerator cost are made as a function of the transmission line conditions, heat leak, and conductor losses.

Refrigerator reliability is of paramount importance in choosing a refrigeration scheme since transmission line outage due to refrigeration failure simply cannot be tolerated. However, this facet would require an extensive experimental study, which is outside the scope of this report. 


\section{REFRIGERATION ANALYSIS - LOW TEMPERATURE END}

We have chosen to analyze the three low temperature refrigeration schemes shown in figure 2.1. These cycles, which were selected as being the most practical, are the Brayton cycle with the expander before the load, scheme 1; the Brayton cycle with the expander after the load, scheme 2; and the Brayton cycle with a separate supercritical helium loop and circulating pump, scheme 3.

Figure 2.2 is an example of what a complete practical refrigerator might look like with scheme 1 attached to the bottom. The expanders at intermediate temperatures are required to reduce the upper heat exchangers to reasonable size and to compensate for any adverse imbalance in the specific heat of the helium refrigerant. The fraction of the compressor flow which must be diverted through the intermediate expanders is identical to the fraction of the total irreversibilities which occur in the upper portion of the refrigerator.

As mentioned in the introduction, certain conditions of constancy must be observed in making comparisons between refrigerators. For the transmission line, we hold the pressure and temperature at the exit and the pressure drop along the line constant. The temperature at the exit, rather than some mean temperature in the line, is held constant since it is the highest temperature that will determine whether or not the line will go normal.

For the expander, the proper condition of constancy is constantexpander efficiency. In practice, expander efficiency may not remain constant. For instance for turbo-expanders the efficiency generally increases with size, so that for the same flow rate, the efficiency tends to decrease with temperature. Rather than tie this study to a particular type or brand of expander, however, we adopt the simplest and most general criterion of constant efficiency. For the heat 


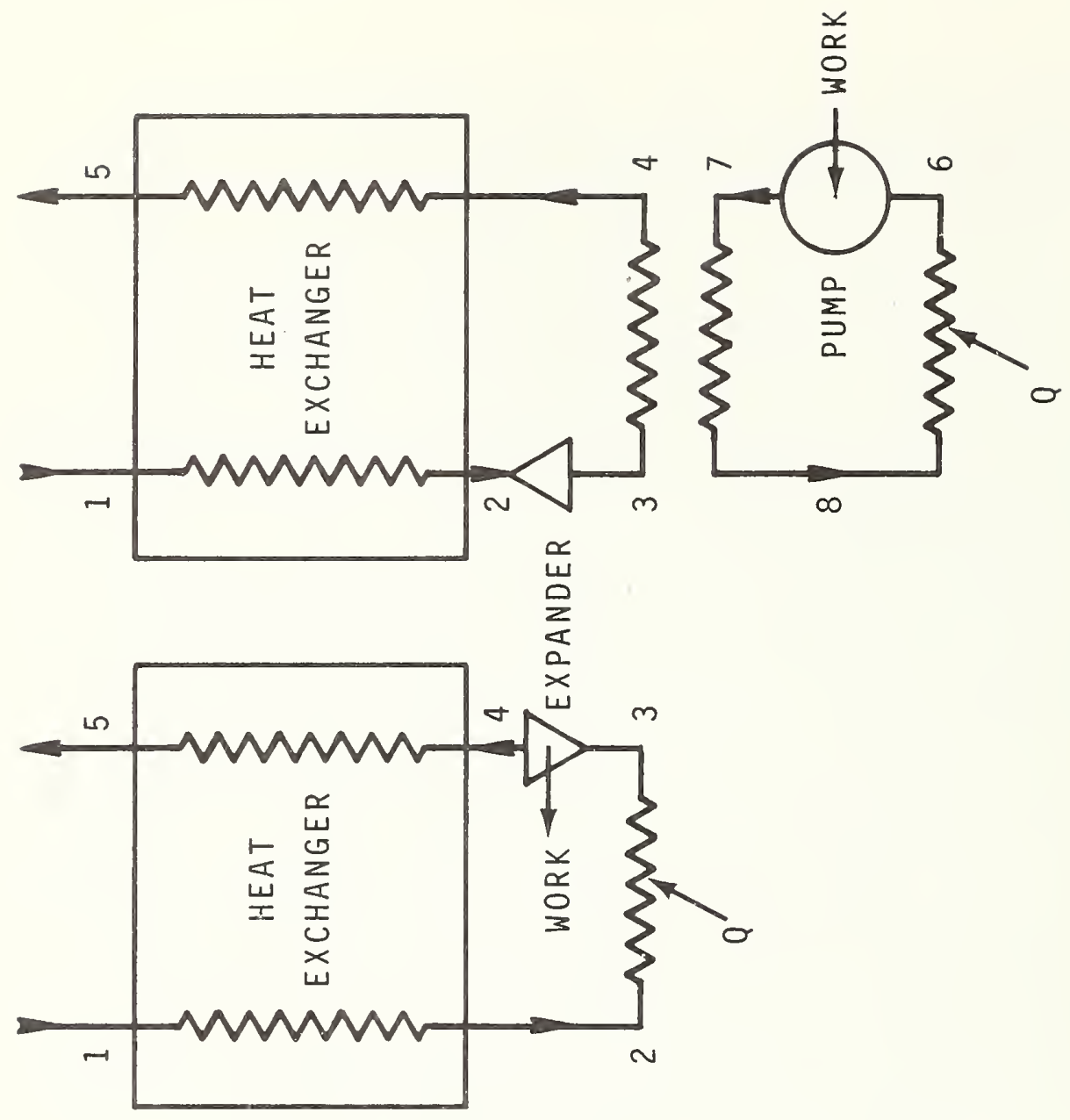

$m$
$\sum_{W}^{W}$
$\stackrel{J}{I}$

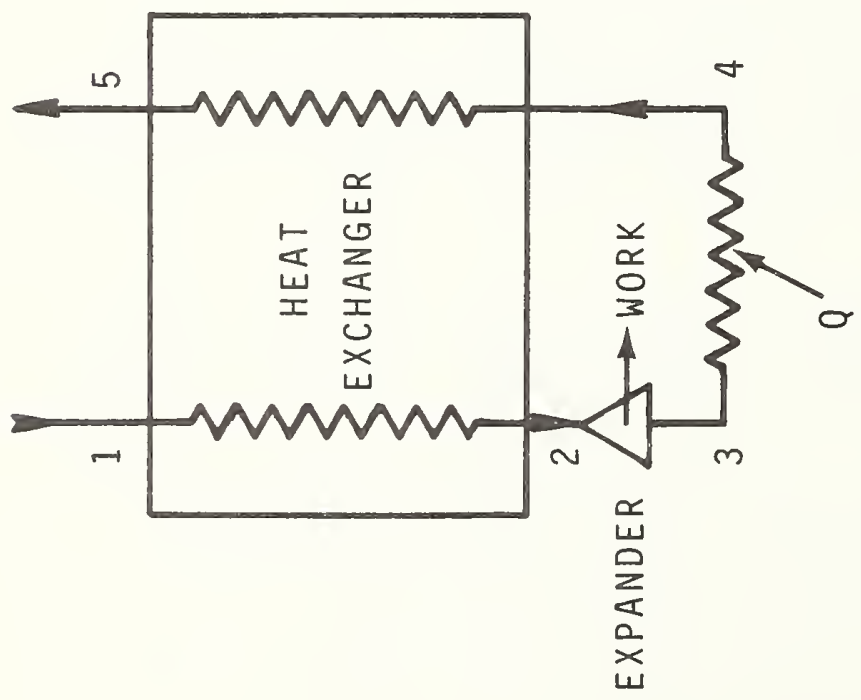

崩

0.0
.
0
0
$D$

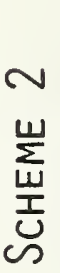

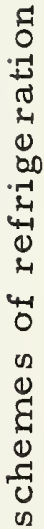

نี 


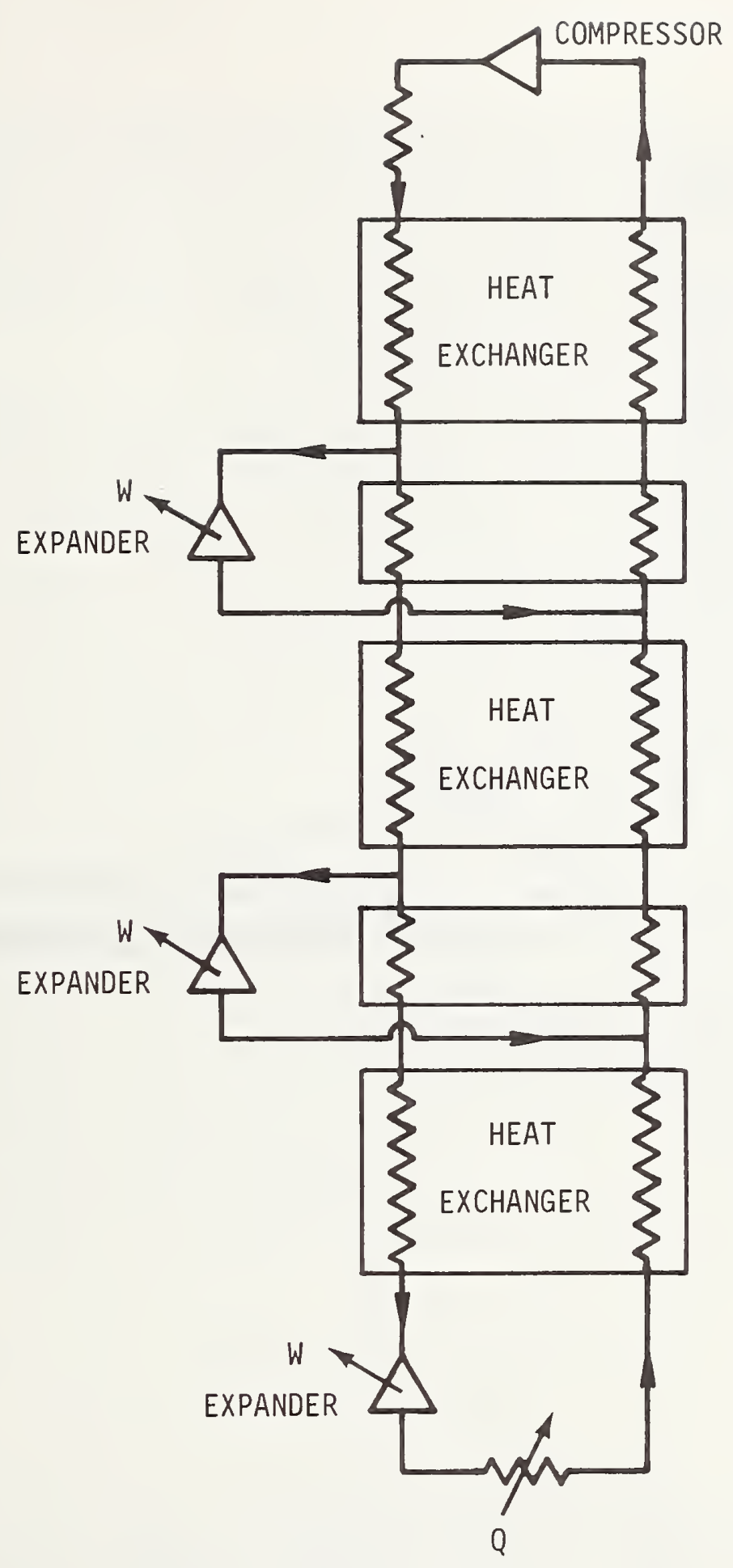

Figure 2.2 One candidate refrigerator using scheme 1 at the cold end. 


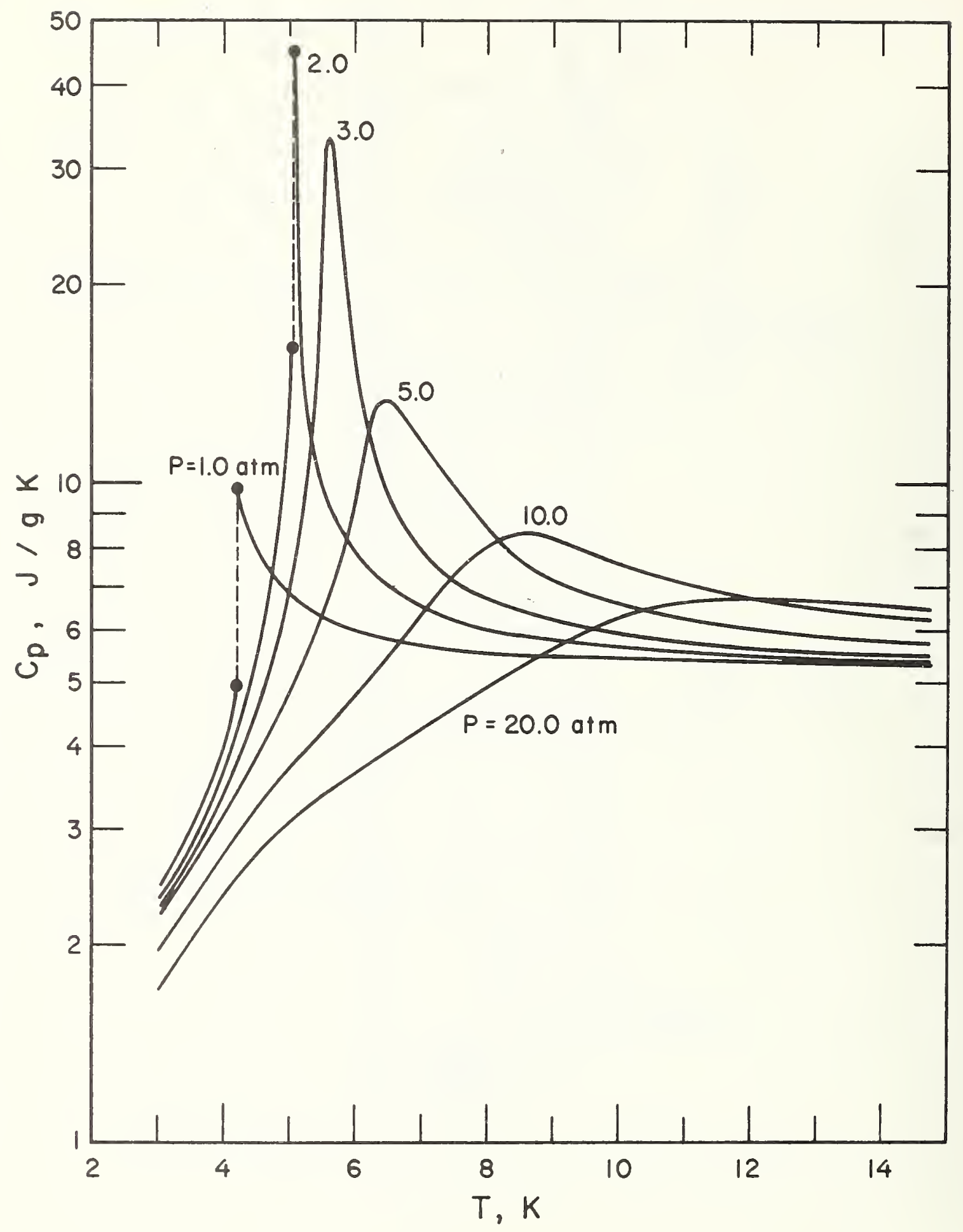

Figure 2.3 Specific heat of helium as a function of temperature for several pressures. 
exchanger, we have chosen to hold the quantity $\mathrm{AU} / \stackrel{\mathrm{m}}{\text { constant, where }}$ $A$ is the heat transfer area on one side of the heat exchanger, $U$ is the overall heat transfer coefficient, and $\stackrel{\circ}{\mathrm{m}}$ is the mass flow rate.

\section{1 Heat Exchanger Analysis}

Typically, in refrigeration cycle analyses, the warm end $\Delta \mathrm{T}$ of the heat exchanger is held constant, or in some cases the heat exchanger effectiveness is held constant. If the relative values of the specific heats of the helium in the two sides of the heat exchanger remain constant, then the size of the heat exchanger (for a given flow rate) will be constant for the constant effectiveness condition. For the constant $\Delta \mathrm{T}$ condition, the size for a given flow rate will be proportional to the heat transferred, or approximately proportional to the temperature span of the heat exchanger.

Unfortunately, for helium the specific heat is very ill-behaved at low temperature (see figure 2.3) so that we can no longer hold the heat exchanger size constant by use of these simple and convenient relationships. Instead, we must numerically solve the diffe rential equations of the heat exchanger.

Consider a differential element of a counterflow heat exchanger.

Then

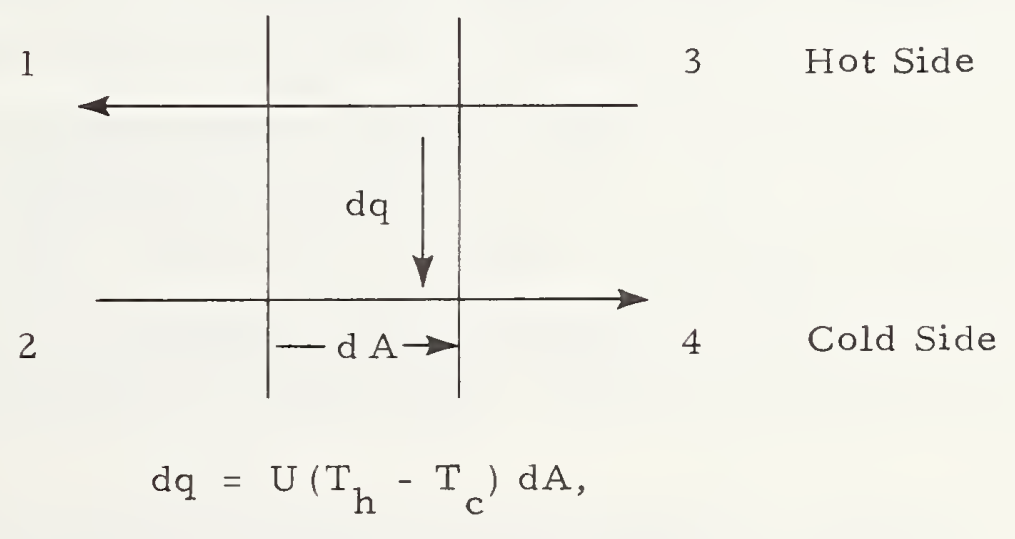

and

$$
\mathrm{dq}=\stackrel{\circ}{\mathrm{m}}_{\mathrm{h}} \mathrm{dH} \mathrm{H}_{\mathrm{h}}=\stackrel{\circ}{\mathrm{m}}_{\mathrm{c}} \mathrm{dH} \mathrm{c}_{\mathrm{c}} .
$$


Equating (1) and (2), we obtain:

$$
\mathrm{dH}_{\mathrm{h}}=\frac{\mathrm{AU}}{\stackrel{\circ}{m}_{h}}\left(\mathrm{~T}_{\mathrm{h}}-\mathrm{T}_{\mathrm{c}}\right) \mathrm{d} \psi,
$$

and

$$
\mathrm{dH}_{\mathrm{c}}=\frac{\stackrel{\circ}{\mathrm{m}_{\mathrm{h}}}}{\stackrel{\circ}{\mathrm{m}}_{\mathrm{c}}} \mathrm{dH_{ \textrm {h } }},
$$

whe re

$$
\mathrm{d} \psi=\frac{\mathrm{dA}}{\mathrm{A}}
$$

Because $T_{h}$ and $T_{c}$ are difficult functions of $\mathrm{H}_{h}$ and $\mathrm{H}_{c}$, eqs (3) and (4) must be integrated numerically. The problem is similar to an initial value problem or propagation problem in that initial values at one end (e.g. , $\mathrm{T} 1$ and $\mathrm{T} 2$ ) are used to march through the heat exchanger and obtain the values at the other end ( $\mathrm{T} 3$ and $\mathrm{T} 4$ ). In our cycle analysis, points at opposite ends of the heat exchanger are known (e. g. , $\mathrm{T} 1$ and $\mathrm{T} 3$ or $\mathrm{T} 2$ and $\mathrm{T} 3$ ) so that iteration is required. If $\mathrm{T} 1$ and $\mathrm{T} 3$ are specified together with the heat exchanger parameter, $\mathrm{AU} / \stackrel{\circ}{\mathrm{m}}_{\mathrm{h}}$, then a value of $\mathrm{T} 2$ is estimated and eqs (3) and (4) are numerically integrated to obtain a value for $\mathrm{T} 3$. The process is repeated until the calculated $\mathrm{T} 3$ agrees with the specified $\mathrm{T} 3$ to within the allowed error $(0.01 \mathrm{~K})$. Convergence is usually obtained in 3 to 7 steps.

To obtain a feeling for the significance of the quantity $A U / \stackrel{\circ}{m}$, one should note that it is related to the commonly used dimensionless heat exchanger size [3], NTU, by the expression $A U / \stackrel{\circ}{m}=(N T U)\left(C_{p}\right)$ since NTU $=\frac{\mathrm{AU}}{\stackrel{\mathrm{\circ}}{\mathrm{m} C_{\mathrm{p}}}}$. 
For a balanced counter flow heat exchange with constant specific heat, NTU is related to the heat exchanger effectiveness, $\epsilon$, by the expression

$$
\epsilon=\frac{N T U}{1+N T U}
$$

A more detailed analysis would consider the ove rall heat transfer coefficient $U$ as a function of temperature and flow rate. For our purpose here, which is a comparative study of refrigeration cycles, such an added complication is not justified.

2. 2 Brayton Cycle with Expander Before the Load, Scheme 1

Because we specify the conditions at the transmission line, the pressure before the expander, P2, is not known. It must be found by iteration. Referring to figure 2.1, the procedure is as follows.

1. The temperature at point 1 , the state at 4 , and the $\Delta \mathrm{P}$ and $\Delta \mathrm{T}$ along the line are fixed.

2. From $T 4, P 4$, and $\Delta \mathrm{P}$ line, and $\Delta \mathrm{T}$ line, state 3 is obtained.

3. An initial estimate of temperature, $T 2$, is made for use in step 4 by the approximation

$\mathrm{T} 2=\mathrm{T} 4+\frac{\mathrm{H}(\mathrm{P} 4, \mathrm{~T} 1)-\mathrm{H}(\mathrm{P} 4, \mathrm{~T} 4)}{(\mathrm{AU} / \mathrm{m})}$.

4. The pressure at 2 is estimated by the perfect gas relationship $P 2=\frac{P 3}{\left[\left(\frac{T 3-T^{2}}{\eta_{e} T^{2}}\right)+1\right]_{p}^{C / R}}$.

5. The pressure at 1 is obtained for this trial from $\mathrm{Pl}=\mathrm{P} 2(1+\Delta \mathrm{P} / \mathrm{P})$, where $\triangle P / P$ is the relative pressure drop in the heat exchanger. 
6. Since states 1 and 4 are now known (Pl is only estimated), we can obtain states 2 and 5 using the heat exchanger routine.

7. Using the definition of the isentropic engine efficiency (see nomenclature), we can now check if we obtain the correct value for T3.

$\mathrm{H} 3=\mathrm{H} 2\left(1-\eta_{\mathrm{e}}\right)+\eta_{\mathrm{e}} \mathrm{H}(\mathrm{P} 3, \mathrm{~S} 2)$

$\mathrm{T} 3=\mathrm{T}(\mathrm{H} 3, \mathrm{P} 3)$.

8. If the value calculated for $\mathrm{T} 3$ in step 7 does not agree with the value obtained in step 2, then iterate using steps 5 to 7 with a new value for P2. The solution is usually obtained in 3 to 5 iterations.

2. 3 Brayton Cycle with Expander After the Load, Scheme 2

For this scheme, the unknown pressure which must be found by iteration is P4. The computational scheme is as follows.

1. The temperature at point 1 , the state at 3 , and the $\triangle P$ and $\triangle \mathrm{T}$ along the line are fixed.

2. From T3, P3, $\Delta P$ line, and $\Delta T$ line, state 2 is obtained.

3. The pressure at 1 is obtained from

$P 1=P 2(1+\Delta P / P)$.

4. Estimate a value of T4 for step 5 using the approximation

$\mathrm{T} 4=\mathrm{T} 2-\frac{(\mathrm{H} 1-\mathrm{H} 2)}{(\mathrm{AU} / \mathrm{m})}$.

5. Calculate the first trial value of P4 using the ideal gas expression

$P 4=P 3\left[\frac{T 4-T 3}{\eta_{e} \mathrm{~T} 3}+1\right]^{C_{p} / R}$. 
6. The enthalpy at point 4 may now be obtained from the definition of the isentropic engine efficiency,

$$
\mathrm{H} 4=\mathrm{H} 3\left(1-\eta_{\mathrm{e}}\right)-\eta_{\mathrm{e}} \mathrm{H}(\mathrm{P} 4, \mathrm{~S} 3) .
$$

7. Using states 2 and 4, we now solve the heat exchanger equations and obtain a value for $\mathrm{T} 1$.

8. We iterate with steps 6 and 7 until we find a value for P4 which gives a Tl that agrees with the given Tl to within the allowable error $(.01 \mathrm{~K})$. The solution is usually found in 5 to 9 ite rations.

2. 4 Brayton Cycle with a Separate Supercritical Helium Loop and Circulating Pump

This arrangement is simply scheme 1 with a supercritical loop added to the bottom. As soon as states 3 and 4 are determined, the solution proceeds as described in section 2.2. We begin at the load.

1. We specify $T 1, P 4, P 6, T 6, \Delta P$ line and $\Delta \mathrm{T}$ line.

2. State 8 is determined from state $6, \Delta \mathrm{T}$ line, and $\Delta \mathrm{P}$ line. $\mathrm{P} 7$ is calculated from

$\mathrm{P} 7=\mathrm{P} 8(1+\Delta \mathrm{P} / \mathrm{P})$

where $\Delta P / P$ is the relative pressure drop through

the pump loop heat exchanger .

3. The enthalpy at 7 is determined using the definition of isentropic pump efficiency (see nomenclature)

$\mathrm{H} 7=\mathrm{H} 6+\frac{\mathrm{H}(\mathrm{P} 7, \mathrm{~S} 6)-\mathrm{H} 6}{\eta_{\mathrm{P}}}$,

and

$\mathrm{T} 7=\mathrm{T}(\mathrm{H} 7, \mathrm{P} 7)$.

We use the isentropic pump efficiency because it is simpler and less ambiguous than the efficiency based on fluid 
horsepower. If the fluid horsepower efficiency is adequately defined for a compressible fluid, then it can be related to the isentropic pump efficiency.

4. Since we now know state 7 , state 8 , and $P 3$, we have the information required to solve the pump loop heat exchange $r$ problem. We assume a value of $\mathrm{T} 4$ and march through the heat exchanger and obtain a T8. As before, we iterate until the $\mathrm{T} 8$ obtained in this fashion agrees with our previously calculated value.

5. We calculate P3 from

$\mathrm{P} 3=\mathrm{P} 4(1+\Delta \mathrm{P} / \mathrm{P})$,

and states 3 and 4 are determined.

The remainder of the problem is identical with that of scheme 1 and we proceed as before.

\section{5 Comments on the Computations}

The ideal work of compression, Wc, was calculated from the difference in the available work for a steady flow process, $H-T_{0} S$, between states 1 and 5 . This is not identical to the isothermal work of compression in going from $\mathrm{P} 5$ to $\mathrm{Pl}$ at temperature $\mathrm{T}_{0}$, although the difference is generally less than a few percent. The availability function is used because it gives the minimum work for a reversible process.

Two sources were used for the helium properties. For all properties except $H(P, S)$ and $T(P, H)$, the programs of McCarty, based on his equation of state $[4,5]$, were used. For $H(P, S)$ and $\mathrm{T}(\mathrm{P}, \mathrm{H})$, we used equations developed by Arp [6].

McCarty's work will undoubtedly stand for some time as the fundamentally accurate helium state equation, giving both the PVT 
surface and properties such as specific heats, compressibilities, etc., which are related to the derivatives of the PVT surface. For practical analysis of refrigeration and flow problems, however, the independent state parameters should be the enthalpy (related to heat input), pressure (related to flow friction factors), and sometimes the entropy (related to system reversibility), rather than the density and the temperature which are the independent parameters of McCarty's equations. This is in no sense a criticism of McCarty's work since all fundamental theories and equations of fluid properties are based on density and temperature expansions. But as a result, the equations are very cumbersome to use in engineering analysis. For example, a double iteration must be done to find density and temperature and then other properties of interest from a given pressure and enthalpy. Such a procedure is time consuming and very costly, and has been a significant limitation to the refrigeration and fluid flow analysis to date.

Consequently, Arp developed four new state equations for helium based on McCarty's work. These are $\mathrm{S}(\mathrm{P}, \mathrm{H})$, which calculates entropy from pressure and enthalpy; $H(P, S)$, which calculates enthalpy from pressure and entropy; $T(P, H)$, which calculates temperature from pressure and enthalpy; and $\mathrm{V}(\mathrm{P}, \mathrm{H})$, which calculates the specific volume. Use of the function $T(P, H)$ resulted in a reduction in computer time of two orders of magnitude in the heat exchanger calculations. Without this function, interpolation in a table of properties would have been required since McCarty's equations required several minutes of computer time for each heat-exchanger calculation.

\section{REFRIGERATION ANALYSIS - HIGH TEMPERATURE END}

In turning our attention now to the warmer portion of the refrigerator, it is instructive to ask why more than a simple counter flow heat exchanger may be required. There are two reasons. First, the size of 
the heat exchanger necessary to achieve the required value of T1 - T5 would be enormous. Second, in some cases the slight imbalance in the specific heats of the two helium streams is such that the heat exchanger becomes pinched and negative temperature differences would result.

Grassmann and Kopp [7] have pointed out that the heat exchanger losses are minimized if the $\Delta \mathrm{T}$ is proportional to the temperature. Thus, several heat exchangers spanning the range from $300 \mathrm{~K}$ to $30 \mathrm{~K}$ are desirable if the losses are to be kept low.

Three possible arrangements for the warm end of the refrigerator which use two balanced flow-counterflow heat exchangers are shown in figure 3.1. Scheme $A$ is the most common arrangement. To have low losses, this arrangement must use a sufficiently high pressure ratio across the expander so that the temperature span along the unbalanced flow heat exchanger is large compared to the temperature difference across the exchanger.

Scheme B is less common, although it has seen some use in liquefiers. Its advantage is that, in principle, it can be used in a cycle of any pressure ratio. Its practical disadvantage is that very low pres sure ratios are usually required across the expanders, limiting its use to specially designed turbo-expanders.

Scheme $C$ is shown primarily as an aid in the analysis, although it has seen some use in hybrid cycles employing Stirling-type machines. Let us consider the problem of minimizing the losses or irreversibilities of the upper part of the refrigerator. This is equivalent to minimizing the total work required to run the refrigerators at temperatures $\mathrm{T} 1$ and $\mathrm{T} 2$ in scheme $\mathrm{C}$.

Referring to figure 3. 1C and taking an approach similar to Kapitza's in his analysis of liquefiers [8], we may write that the heat 


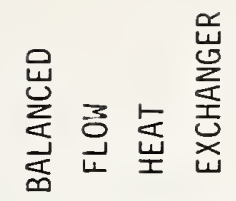
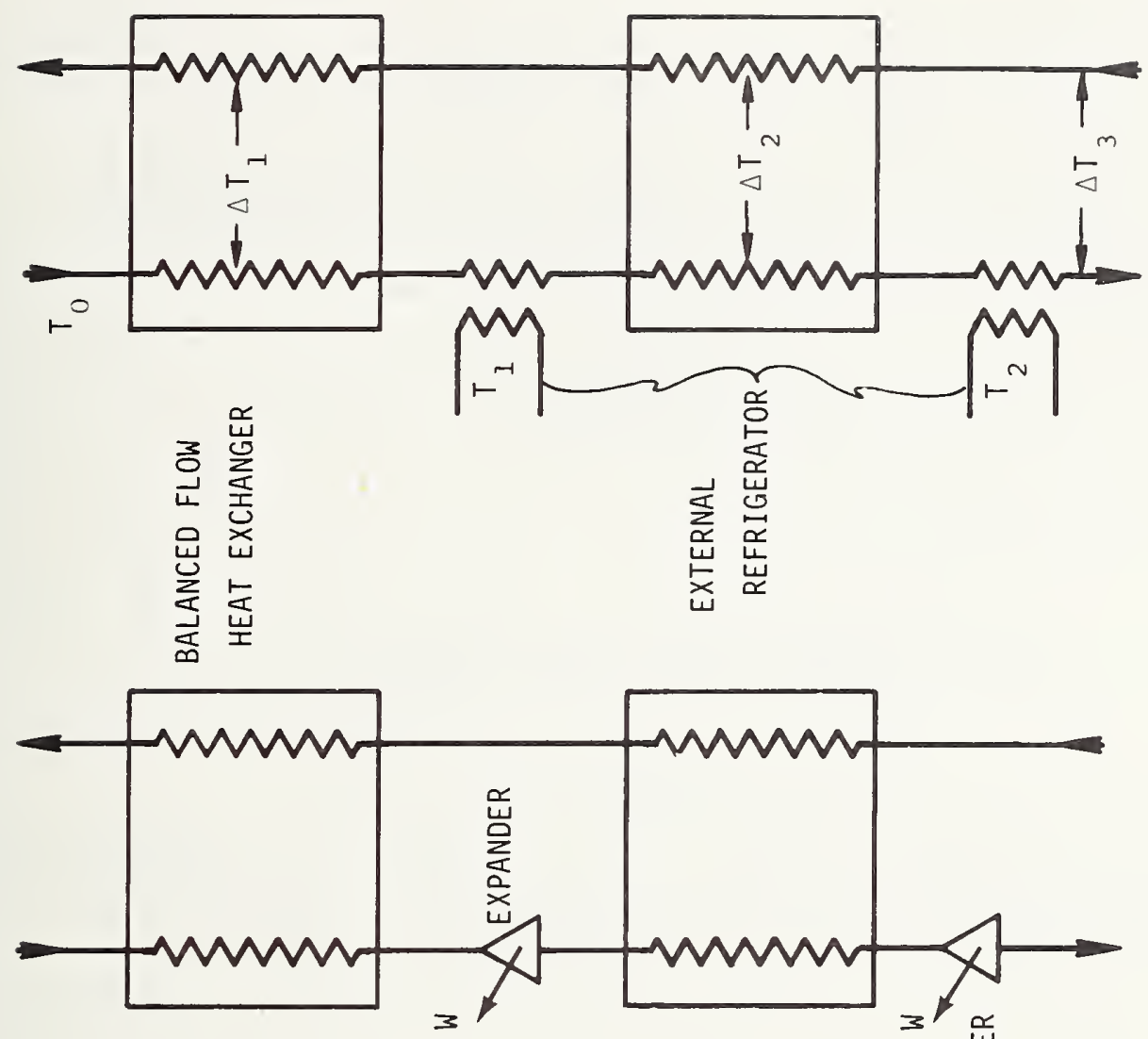

品

$\infty$

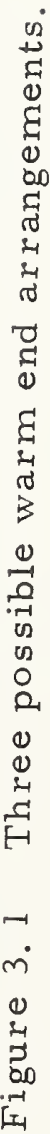

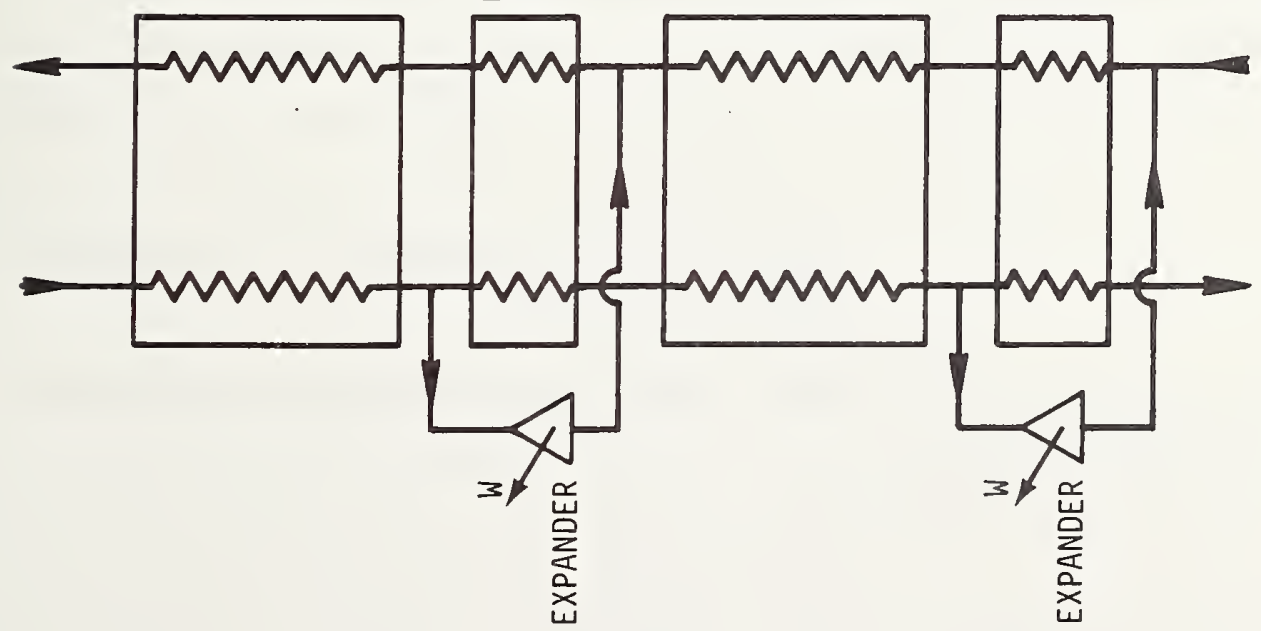

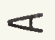


removed at $\mathrm{Tl}$ is

$$
\rho_{1}=\stackrel{\circ}{m}_{1} C_{p}(\Delta \mathrm{T} 1-\Delta \mathrm{T} 2) .
$$

We assume $\Delta \mathrm{T} 1$ and $\Delta \mathrm{T} 2$ to be constant along each heat exchanger. The work required to run this refrigerator is

$$
W_{1}=\frac{Q_{1}}{\eta_{c}} \frac{T_{0}-T_{1}}{T_{1}} \text {, }
$$

or

$$
W_{1}=\frac{m_{1} C_{p}}{\eta_{c}}(\Delta \mathrm{Tl}-\Delta \mathrm{T} 2)\left(\frac{\mathrm{T}_{0}-\mathrm{Tl}}{\mathrm{Tl}} .\right.
$$

An analogous expression may be written for $W_{2}$.

An assumption is required regarding the heat exchangers, and we assume equal effectiveness of the two exchangers. This implies that

$$
\frac{\Delta \mathrm{Tl}}{\Delta \mathrm{T} 2}=\frac{\mathrm{T}_{0}-\mathrm{T} 1}{\mathrm{~T} 1-\mathrm{T} 2}
$$

Eliminating $\Delta \mathrm{T} 2$ from the expression for the sum of the work, and setting $\frac{\partial W}{\partial T l}$ equal to zero, the resulting expression for the value of Tl which gives the minimum work is

$$
\mathrm{T} l=\frac{\mathrm{T}_{0}}{1+\mathrm{T}_{\mathrm{o}}-\mathrm{T}^{2}} .
$$

For $\mathrm{T}_{\mathrm{O}}=300 \mathrm{~K}, \mathrm{~T} 2=30 \mathrm{~K}$, and the heat exchanger effectiveness $=98$ percent, the results are

$$
\begin{aligned}
\mathrm{Tl} & =81 \mathrm{~K} \\
\Delta \mathrm{T} 1 & =4.4 \mathrm{~K} \\
\Delta \mathrm{T}_{16} & =1.0 \mathrm{~K} .
\end{aligned}
$$


Changing $\mathrm{Tl}$ by $\pm 20 \mathrm{~K}$ increases the work by only about 5 percent, but significantly larger variations in $\mathrm{T} l$ cause a rapid increase in the work.

To determine what value might be reasonable for the efficiency, $\eta^{\prime}$, of the external refrigerator, we compared scheme $C$ to scheme B for a typical set of conditions using the values of $\mathrm{Tl}, \Delta \mathrm{Tl}$, and $\Delta \mathrm{T} 2$ listed above. We find that a 70 percent expansion engine efficiency in scheme $B$ is equivalent to a 60 percent of Carnot refrigerator efficiency ( 36 percent for a 60 percent compressor efficiency) in scheme C. Since these values of efficiency seem reasonable, the work calculated in this example $(659 \mathrm{~J} / \mathrm{mol}$ ) is taken as typical for this study.

The total work required to run the refrigerator is the sum of the work required for the two parts. It is given by

$$
\left(\frac{W c}{Q}\right)_{\text {total }}=\left(\frac{W c}{Q}\right)_{\text {cold end }}+\left(\frac{\stackrel{\circ}{Q}}{Q}\right)\left(\frac{W c}{m}\right)_{\text {warm end }} \text {. }
$$

Note that the warm end work per unit of refrigeration is proportional to the flow rate. Thus, when other factors are nearly equal, it is advantageous to select a cycle with a low value of $\stackrel{\circ}{\mathrm{m}} / \mathrm{Q}$. Low mass flow rates are also desirable from the standpoint of load pressure drop, heat exchanger size, and compressor size.

The results of this section are approximate in that it may not always be possible to construct a practical refrigerator with warm end losses as low as we estimate. However, we feel that the advantage gained due to the simplicity and generality of the approach more than compensates for this difficulty.

\section{COLD END RESULTS}

The results of our calculations for the cold end of the refrigerator are presented as plots of Wc/Q vs. the pressure at the exit from the load for constant values of $\Delta \mathrm{T}$ across the load. The values of $\mathrm{Wc} / \mathrm{Q}$ given assume reversible compression, so they must be divided by an 
isothermal compressor efficiency to obtain the work of an actual refrigerator. The work per unit of refrigeration for a complete refrigerator is obtained from eq (7) as discussed in the previous section.

Unless indicated otherwise on the plots, the following parameter values were used in the computations:

Refrigerator heat exchanger size

$$
\mathrm{AU} / \stackrel{\circ}{\mathrm{m}}=1100 \mathrm{~J} / \mathrm{mol}-\mathrm{K}
$$

Pump loop heat exchange $r$ size

$$
\mathrm{AU} / \stackrel{\circ}{\mathrm{m}}=220 \mathrm{~J} / \mathrm{mol}-\mathrm{K}
$$

Relative pressure drop in heat exchanger

$$
\Delta \mathrm{P} / \mathrm{P}=0.01
$$

Temperature at top of refrigerator heat exchanger

$$
\mathrm{T} 1=30 \mathrm{~K}
$$

Expander efficiency

$$
\eta_{\mathrm{e}}=0.70
$$

Pump efficiency

$$
\eta_{\mathrm{p}}=0.50
$$

Pressure drop across the load

$$
\Delta \mathrm{P} \text { load }=1.0 \mathrm{~atm}
$$

Results are given for load exit temperatures of $8 \mathrm{~K}, 10 \mathrm{~K}$, $12 \mathrm{~K}$, and $14 \mathrm{~K}$ and the figures are arranged in that order. Plots of $\stackrel{\mathrm{m}}{\mathrm{Q}} \mathrm{Q}$ are given for each temperature as an aid to calculating the total work for a complete refrigerator. A few results are given for parameter values different from those listed above in order to indicate the effect of these parameters on Wc/Q.

The value of $\mathrm{AU} / \mathrm{m}$ chosen for the heat exchanger corresponds to an NTU of about 50. In a balanced flow exchanger, this is equivalent to an effectiveness of 98 percent. The pump loop heat exchanger size 
$8 \mathrm{~K}$

LOAD EXIT TEMPERATURE 

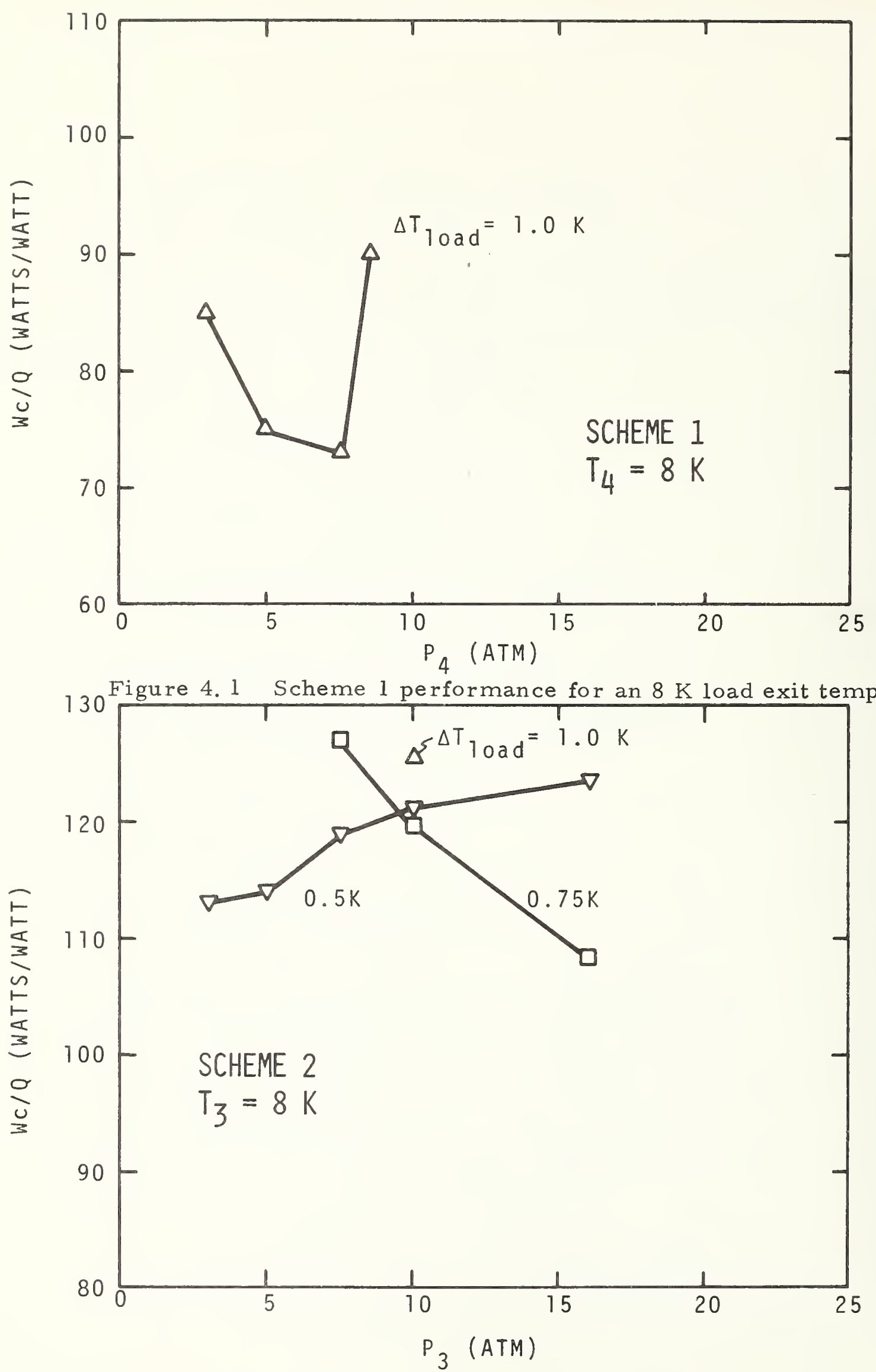

Figure 4.2 Scheme 2 performance for an $8 \mathrm{~K}$ load exit temperature. 
$10 \mathrm{~K}$

LOAD EXIT TEMPERATURE 


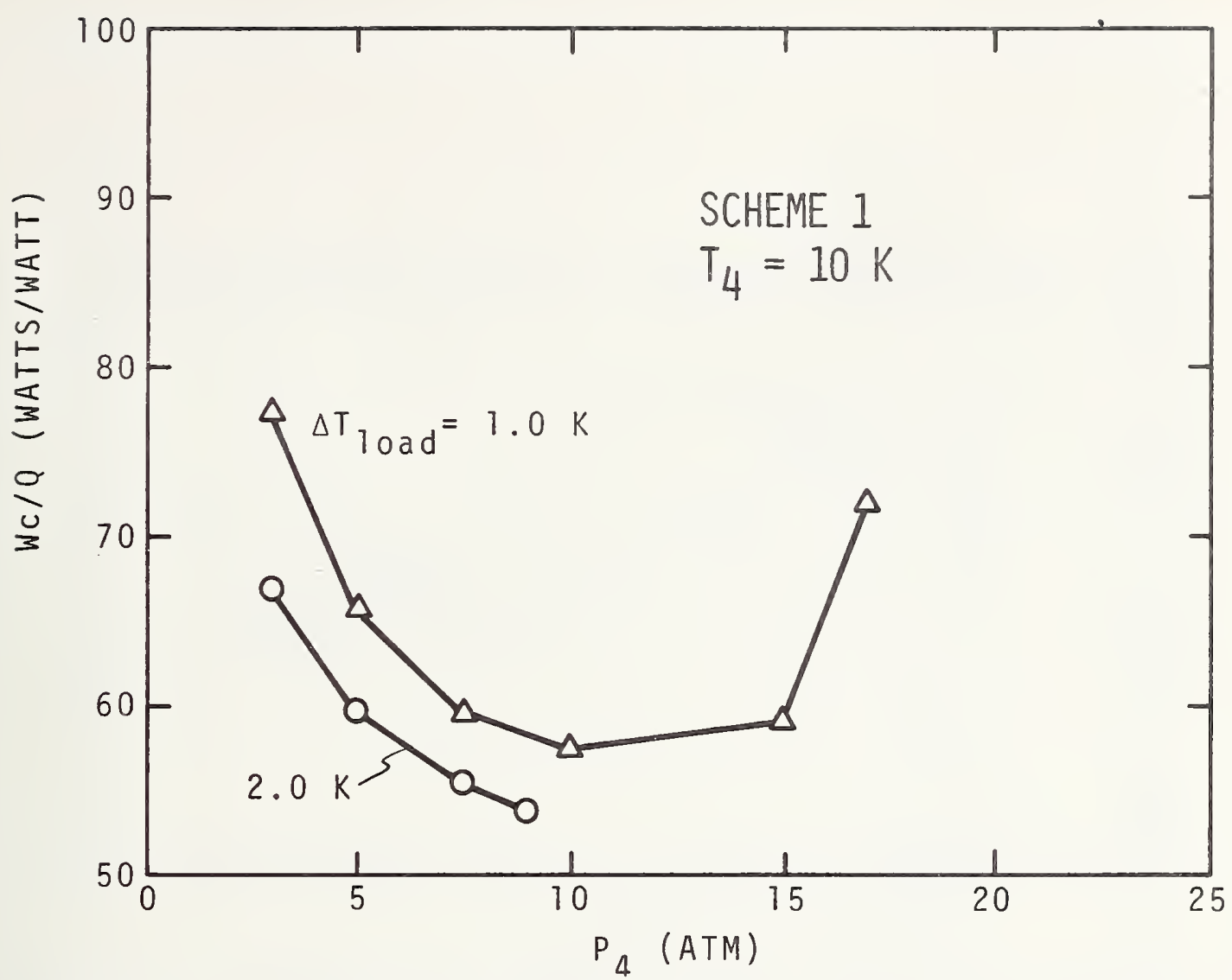

Figure 4. 5 Scheme 1 performance for a $10 \mathrm{~K}$ load exit temperature.

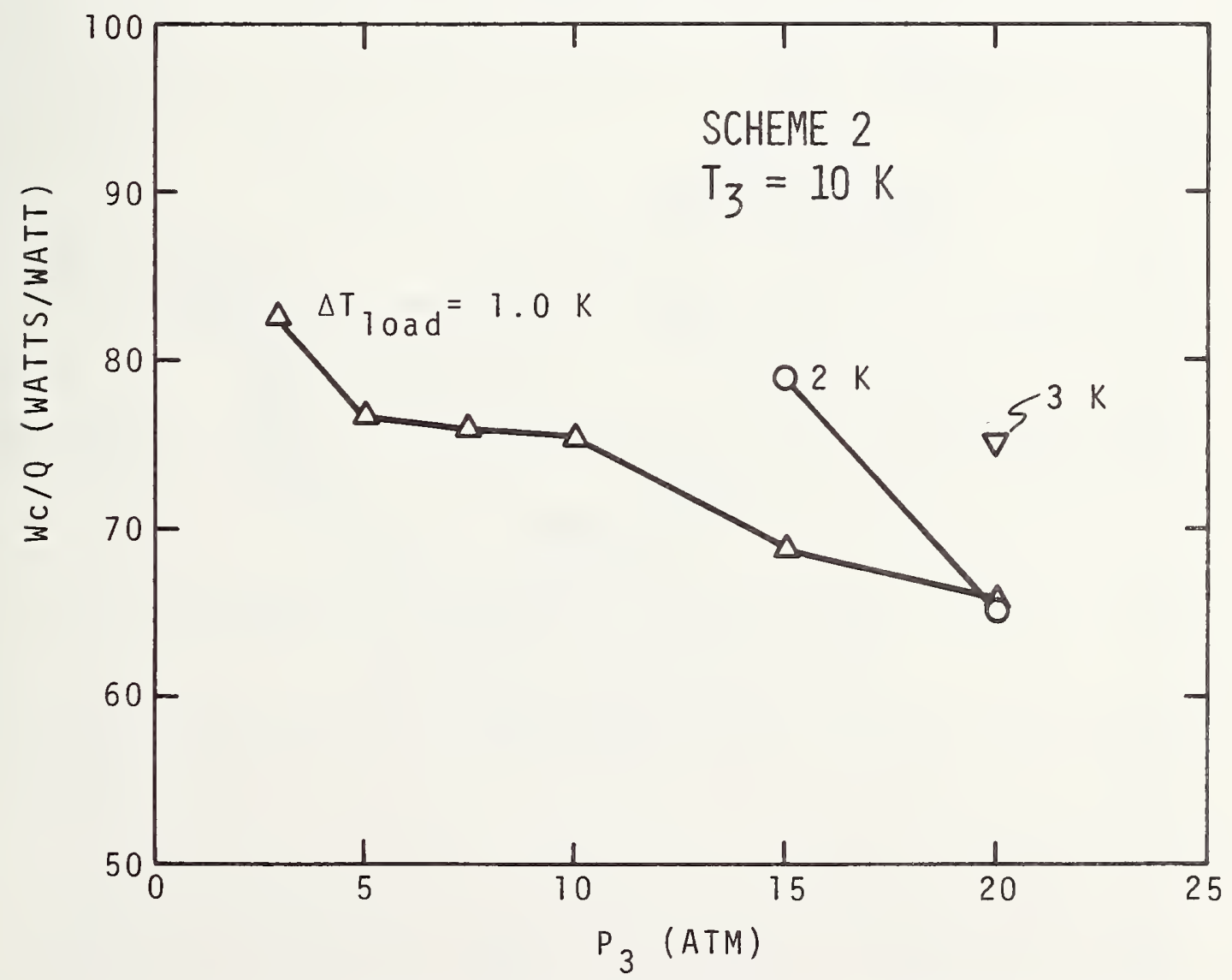

Figure 4.6 Scheme 2 performance for a $10 \mathrm{~K}$ load exit temperature. 


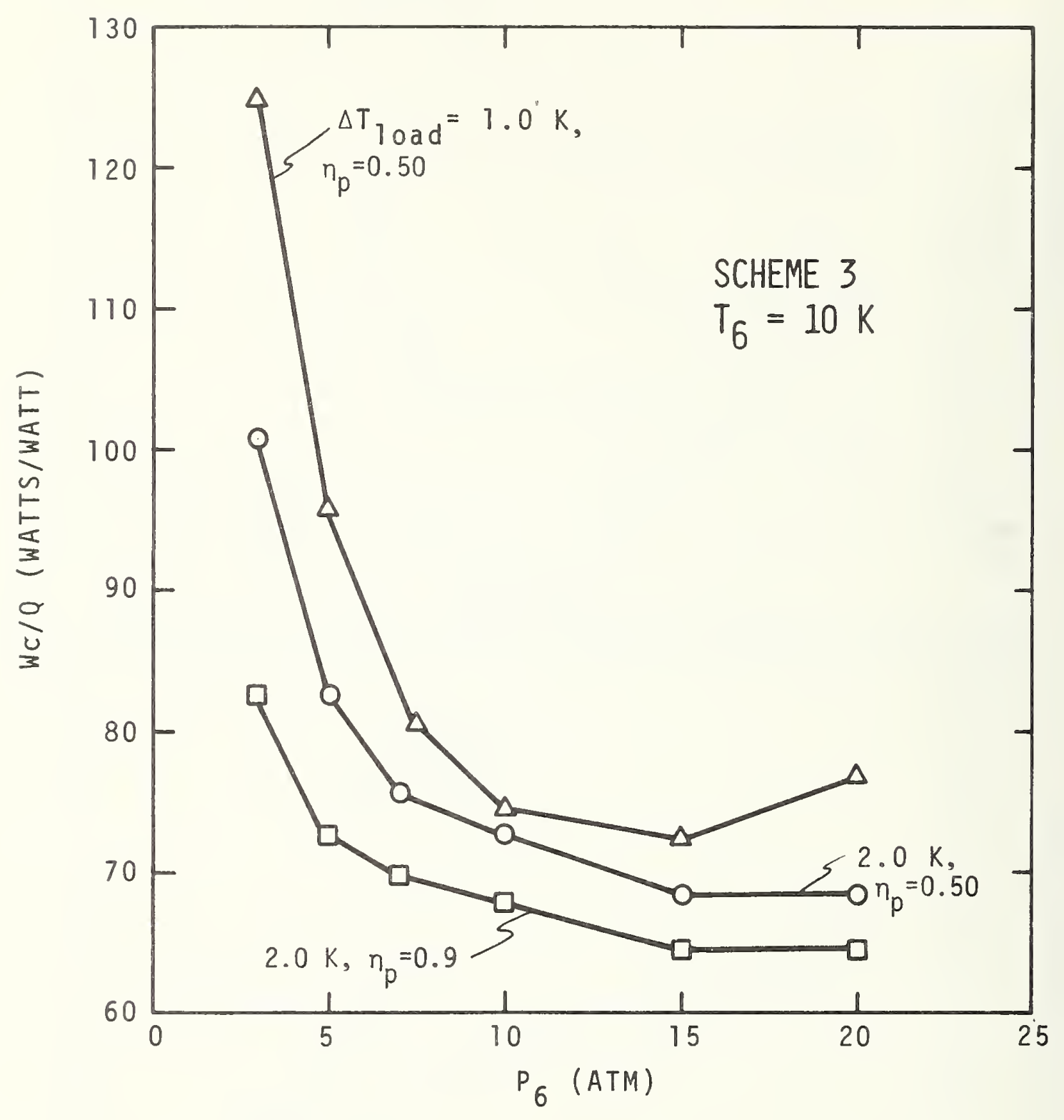

Figure 4.7 Scheme 3 performance for a $10 \mathrm{~K}$ load exit temperature. 


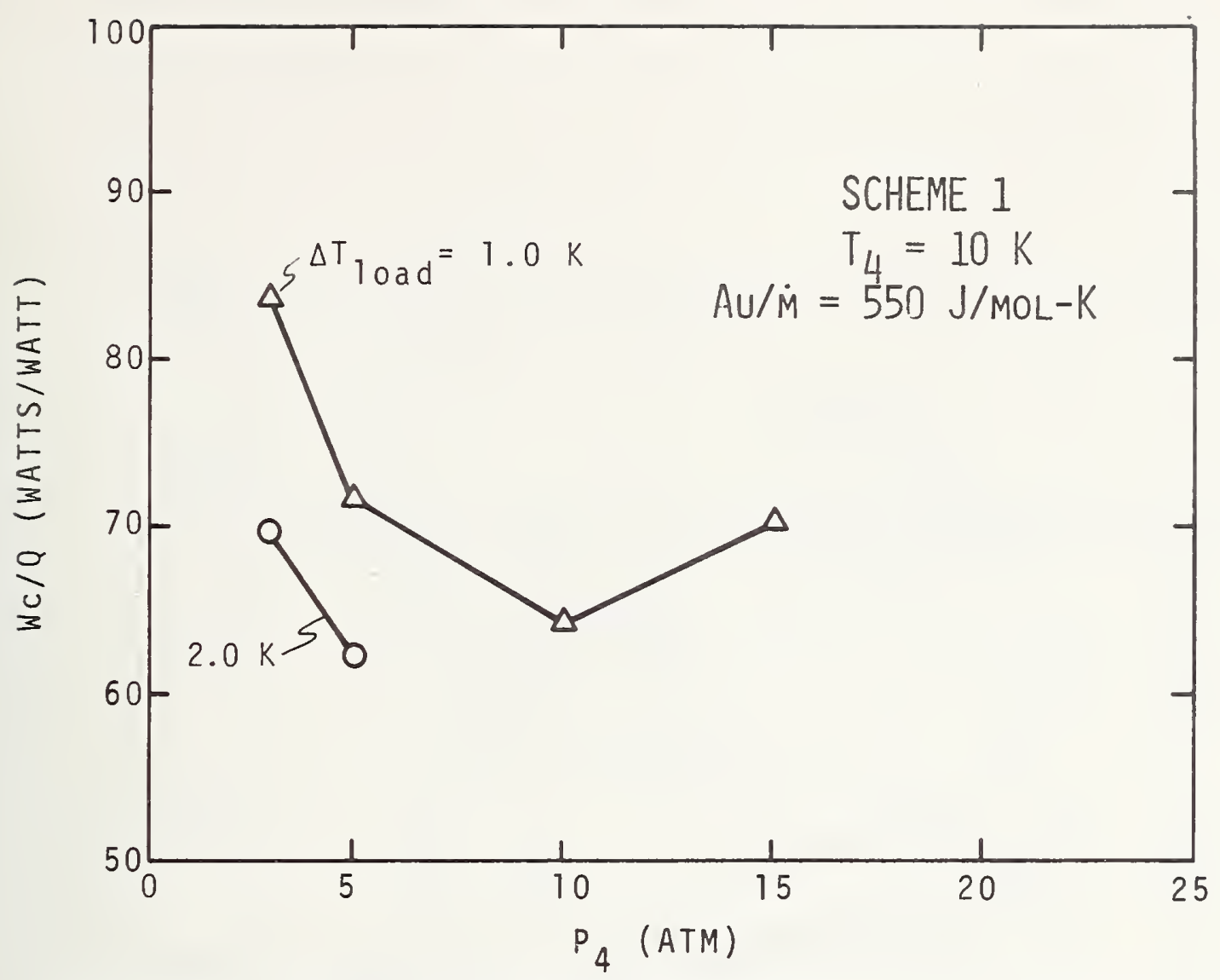

Figure 4.8 Effect of reduced heat exchanger size on the performance of scheme 1 .

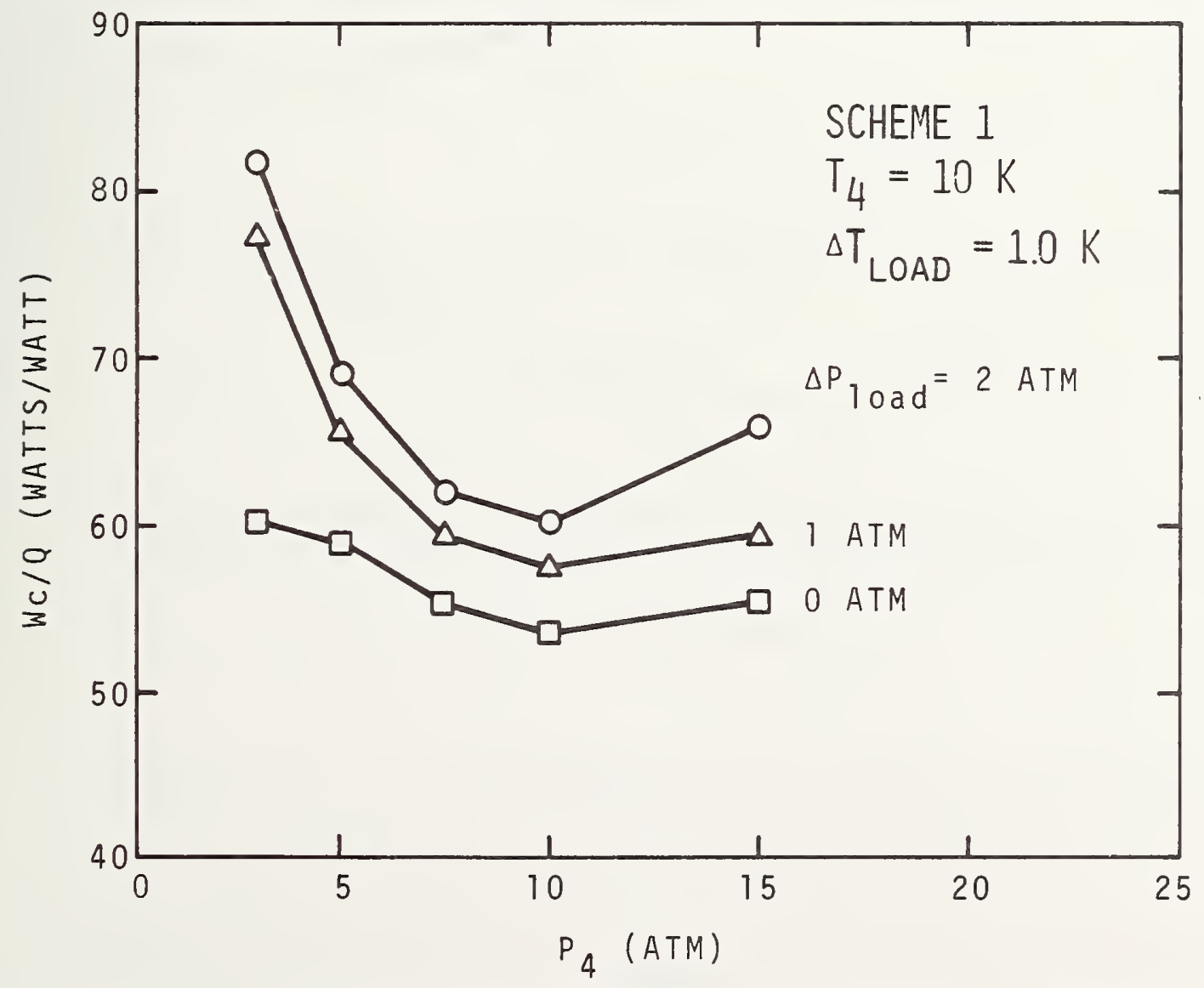

Figure 4.9 Effect of load pressure drop on scheme 1 performance. 


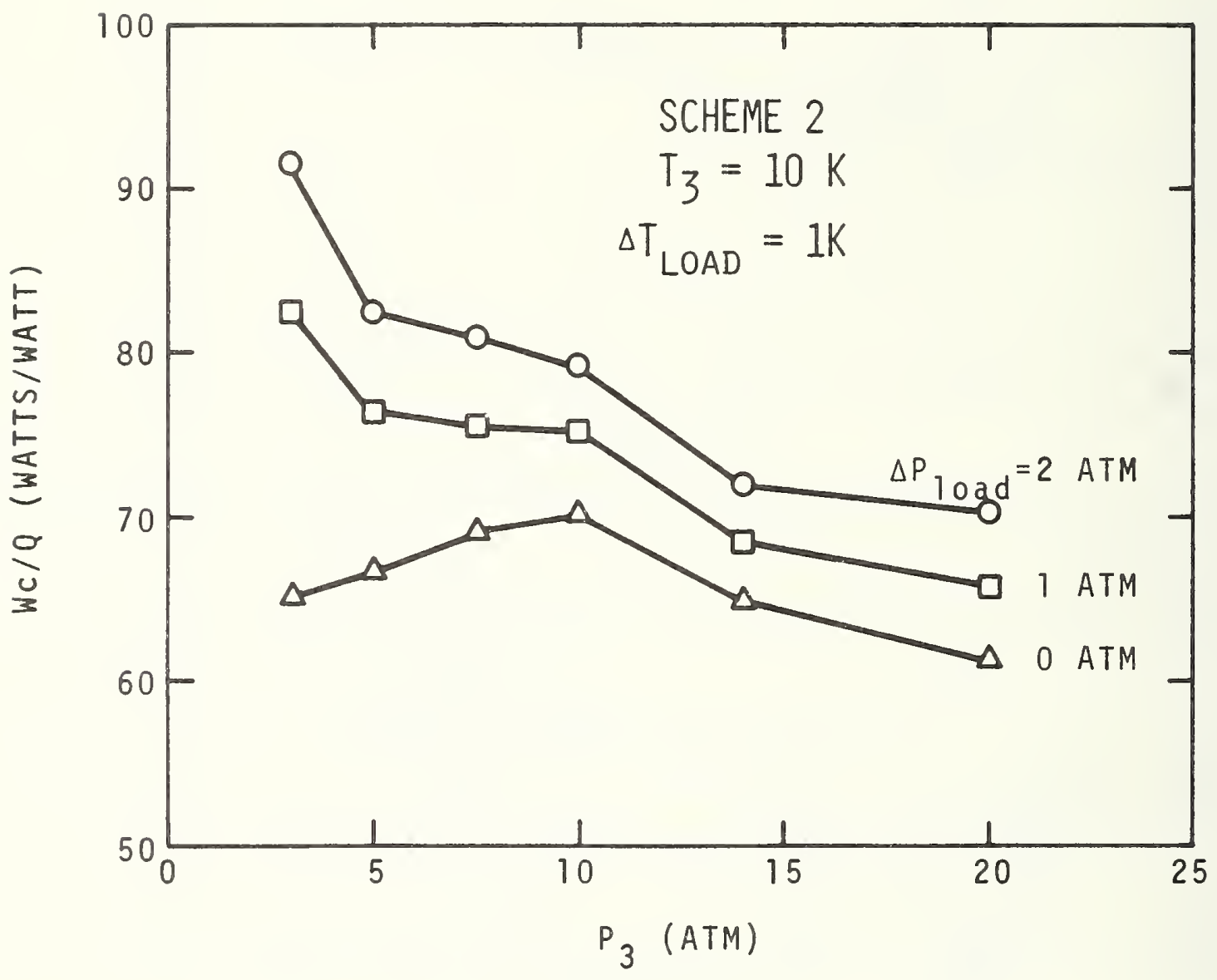

Figure 4.10 Effect of load pressure drop on scheme 2 performance. 


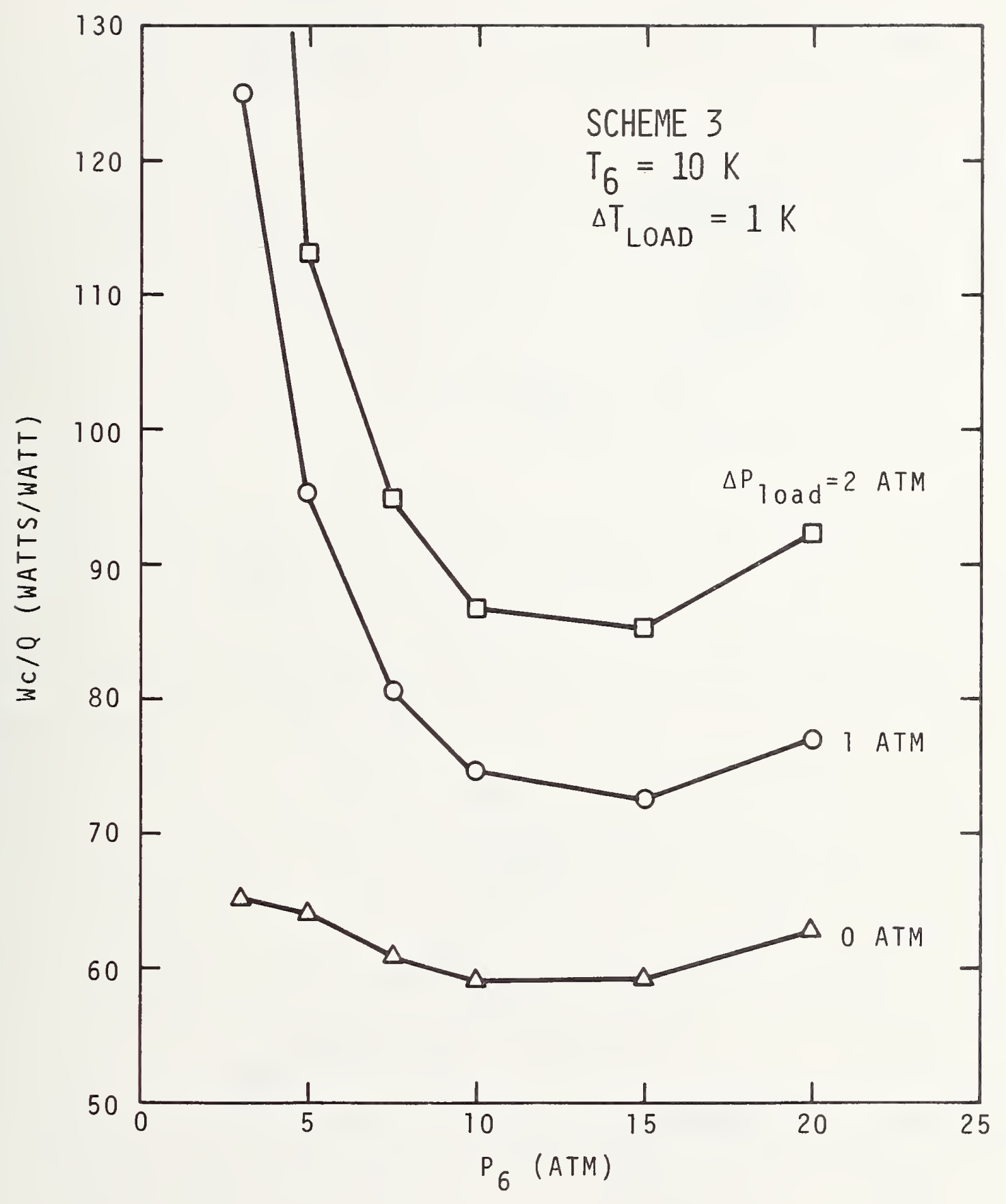

Figure 4.11 Effect of load pressure drop on scheme 3 performance. 
Figure 4.12 Scheme 1 performance for a $10 \mathrm{~K}$ load exit temperature with $80 \%$ engine efficiency.
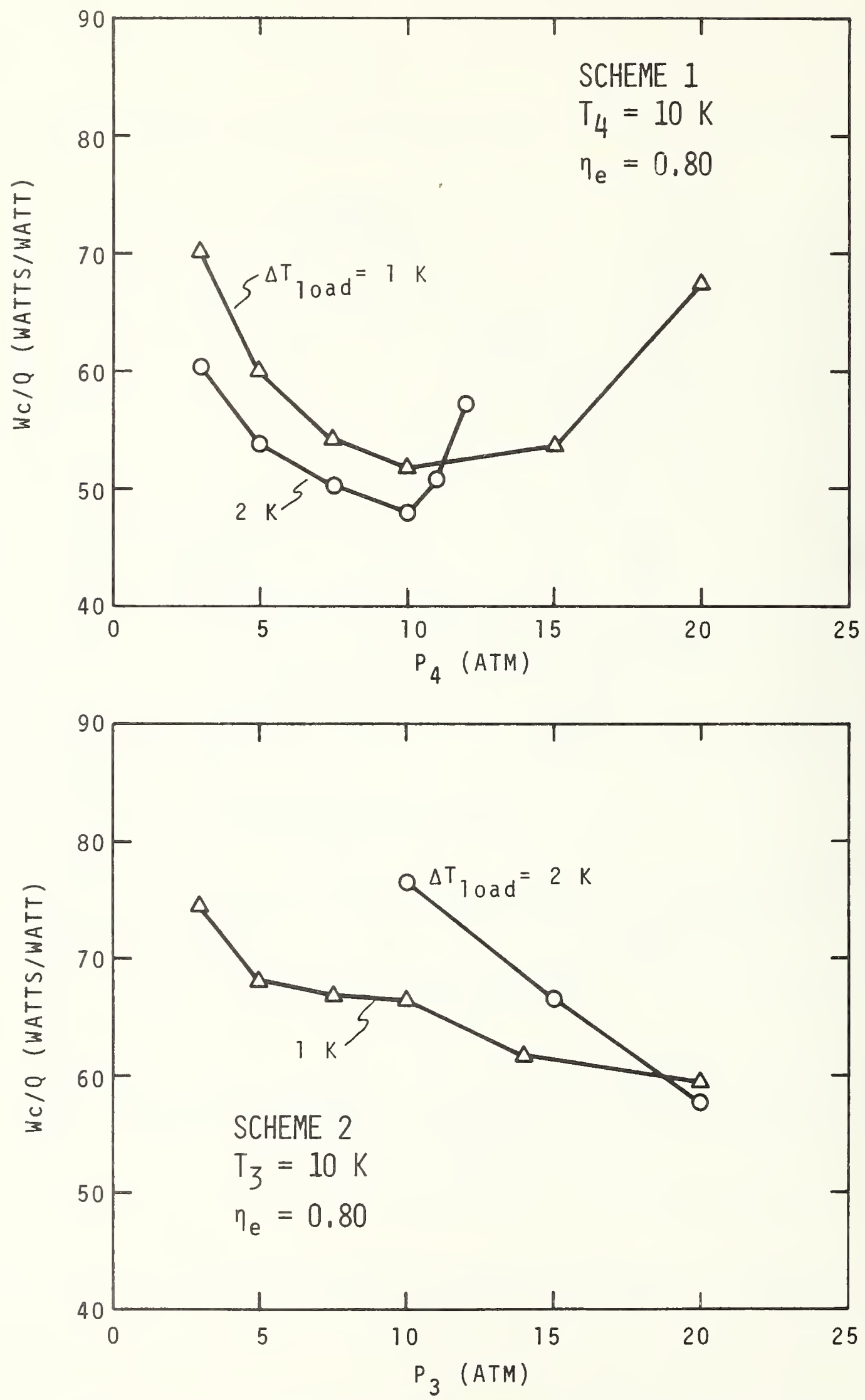

Figure 4.13 Scheme 2 performance for a $10 \mathrm{~K}$ load exit temperature with $80 \%$ engine efficiency. 28 


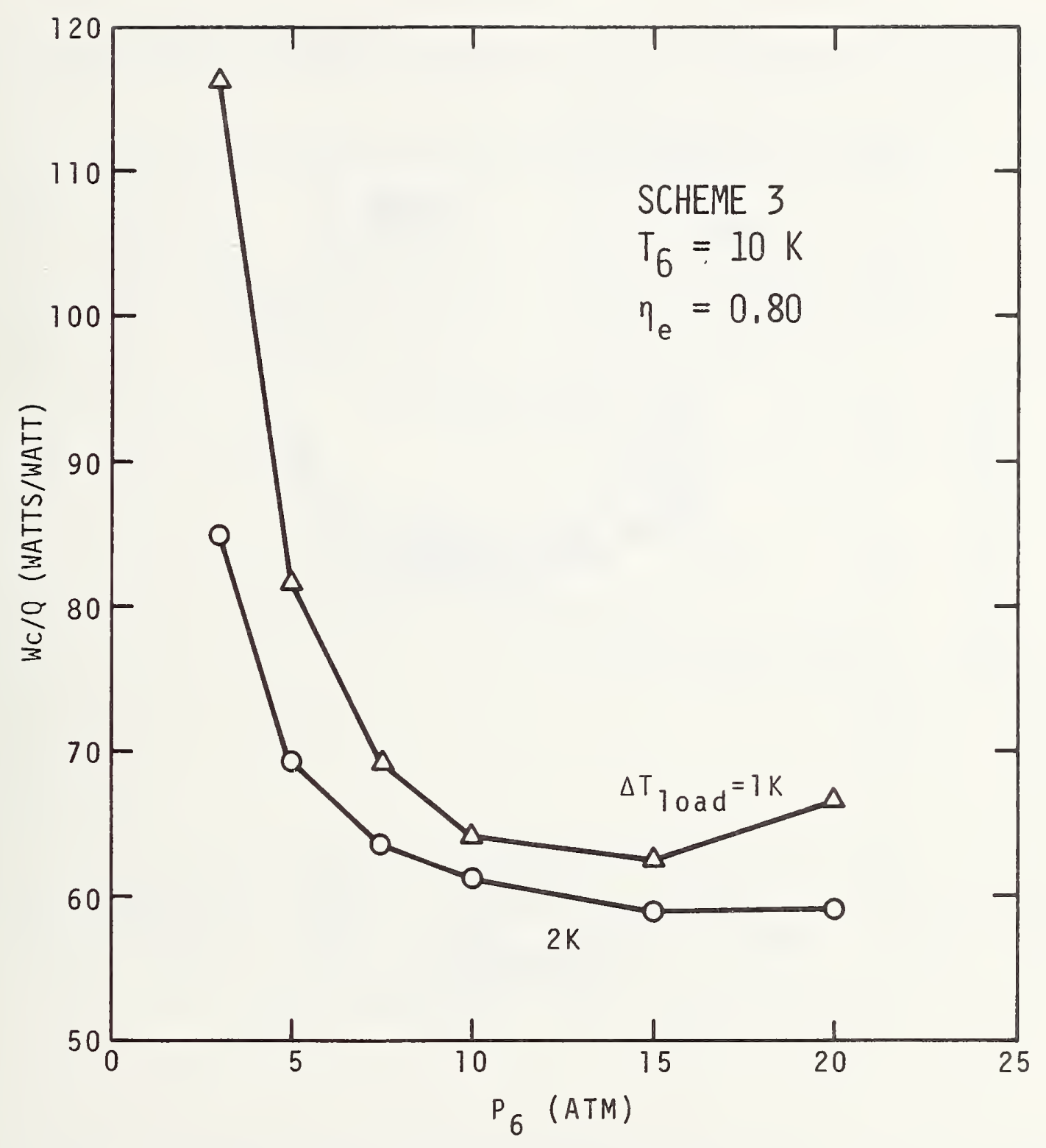

Figure 4.14 Scheme 3 performance for a $10 \mathrm{~K}$ load exit temperature with $80 \%$ engine efficiency. 


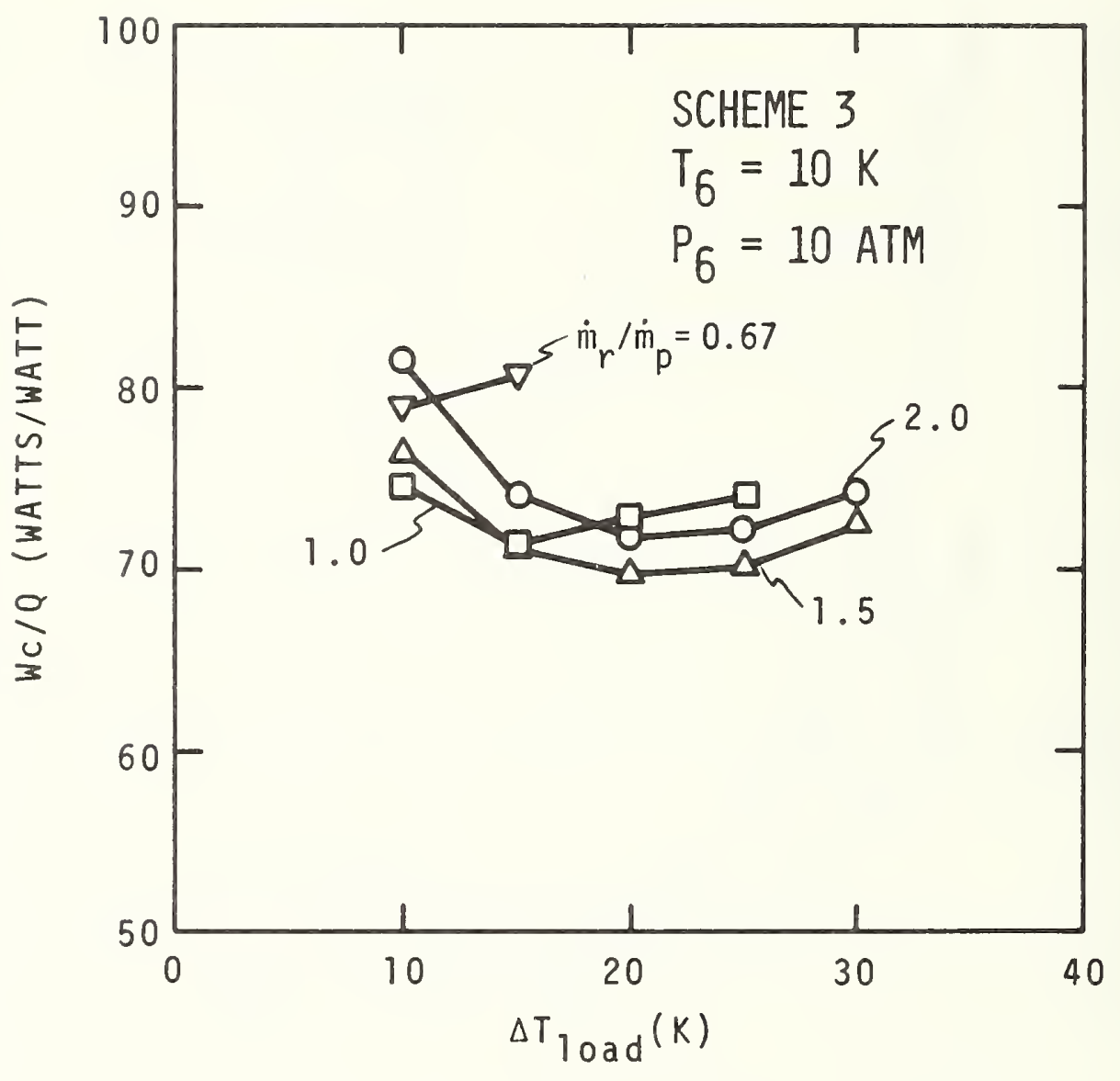

Figure 4.15 Effect of the refrigerator to pump mass flow ratio on the performance of scheme 3. 


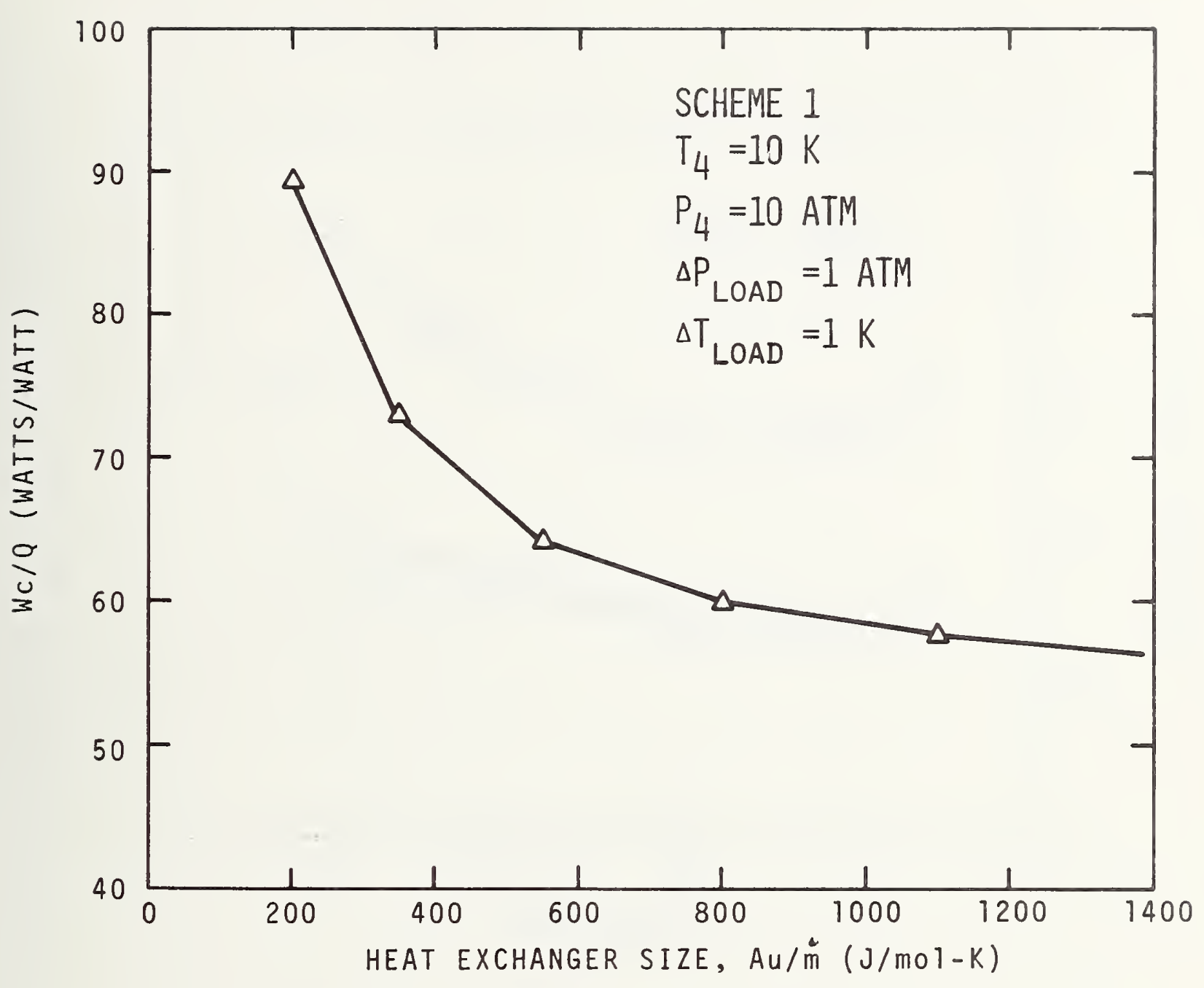

Figure 4.16 Scheme 1 performance as a function of heat exchanger size. 


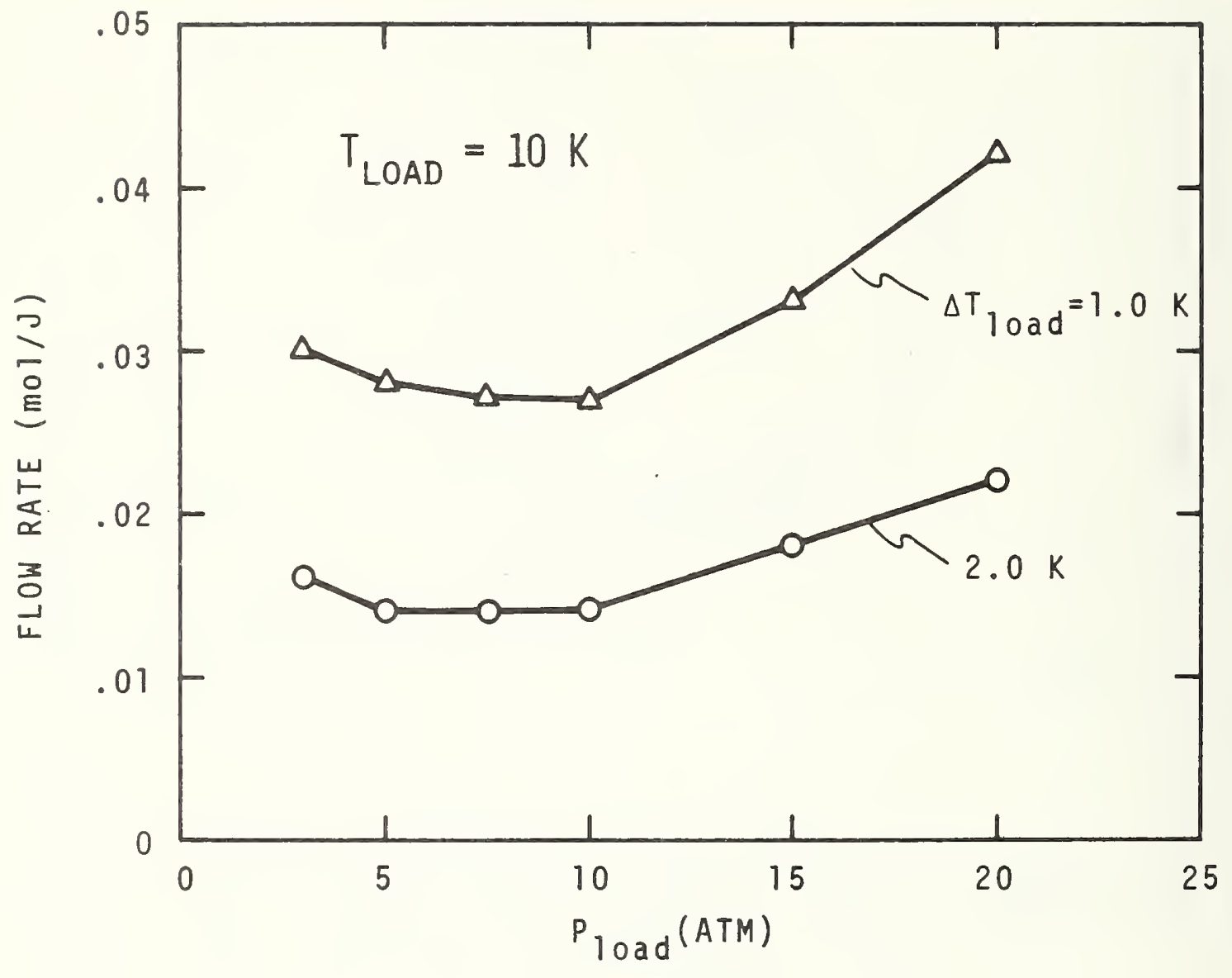

Figure 4.17 Flow rate vs. load pressure for a $10 \mathrm{~K}$ load exit temperature. 
$12 \mathrm{~K}$

LOAD EXIT TEMPERATURE 


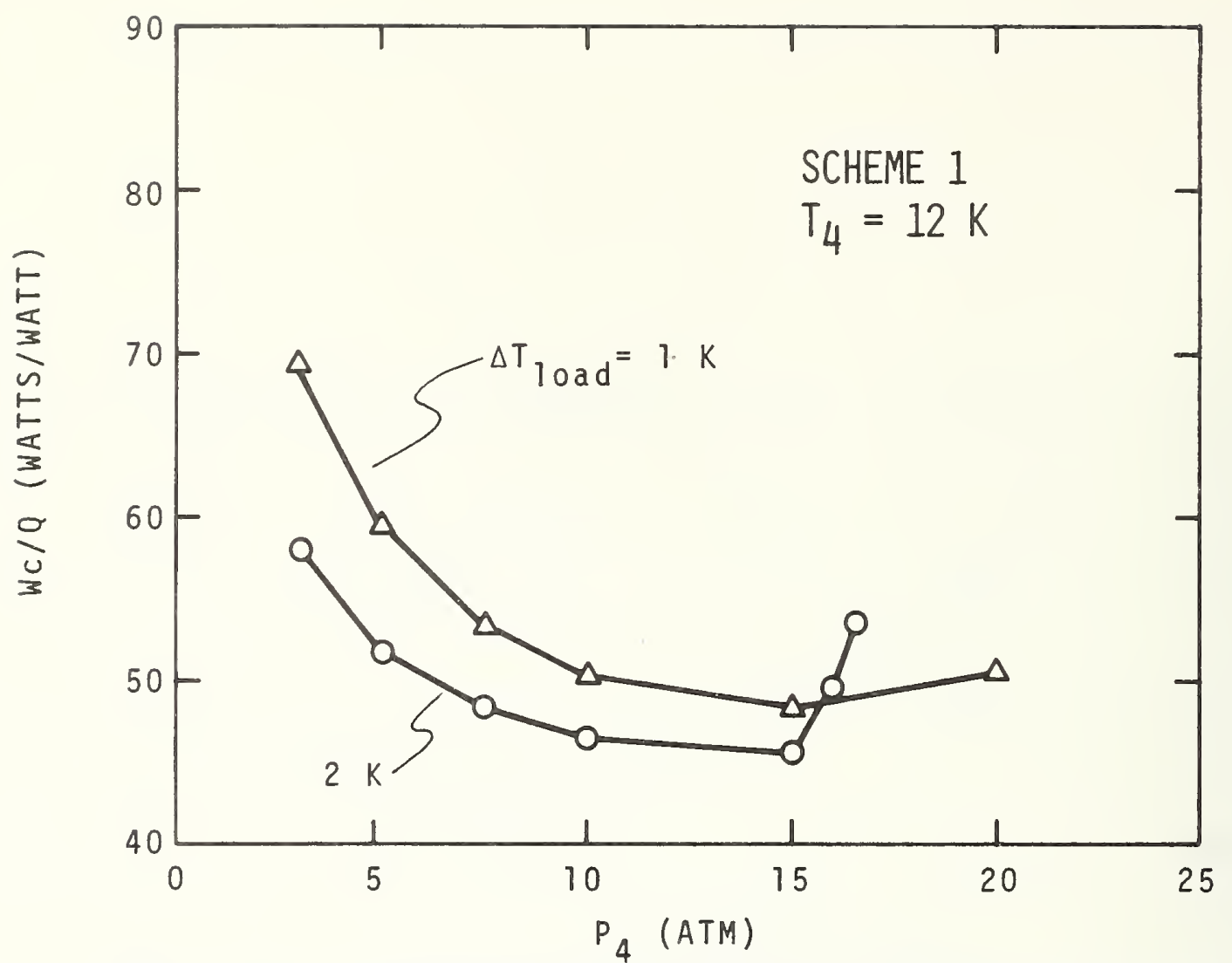

Figure 4.18 Scheme 1 performance for a $12 \mathrm{~K}$ load exit temperature.

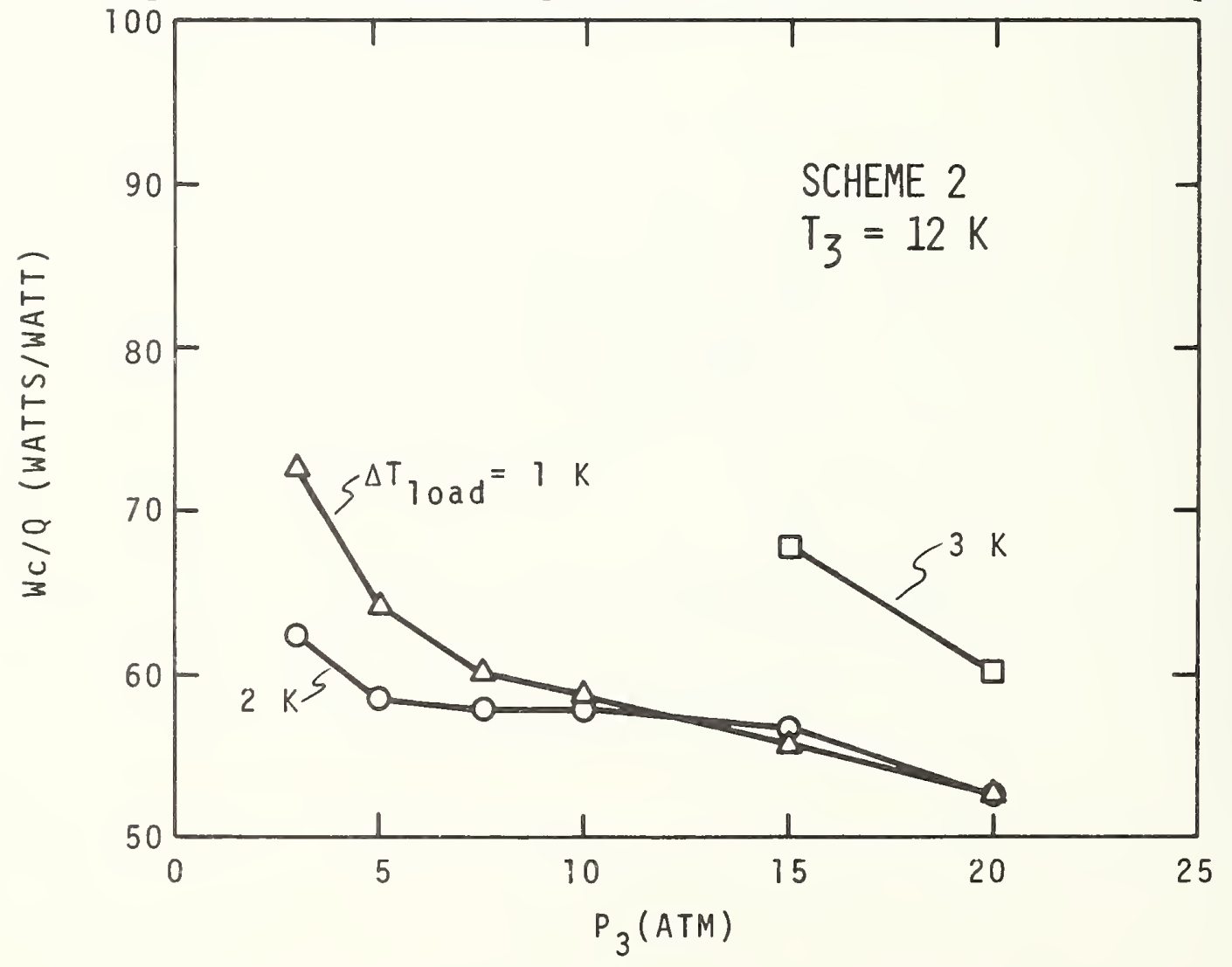

Figure 4.19 Scheme 2 performance for a $12 \mathrm{~K}$ load exit temperature. 


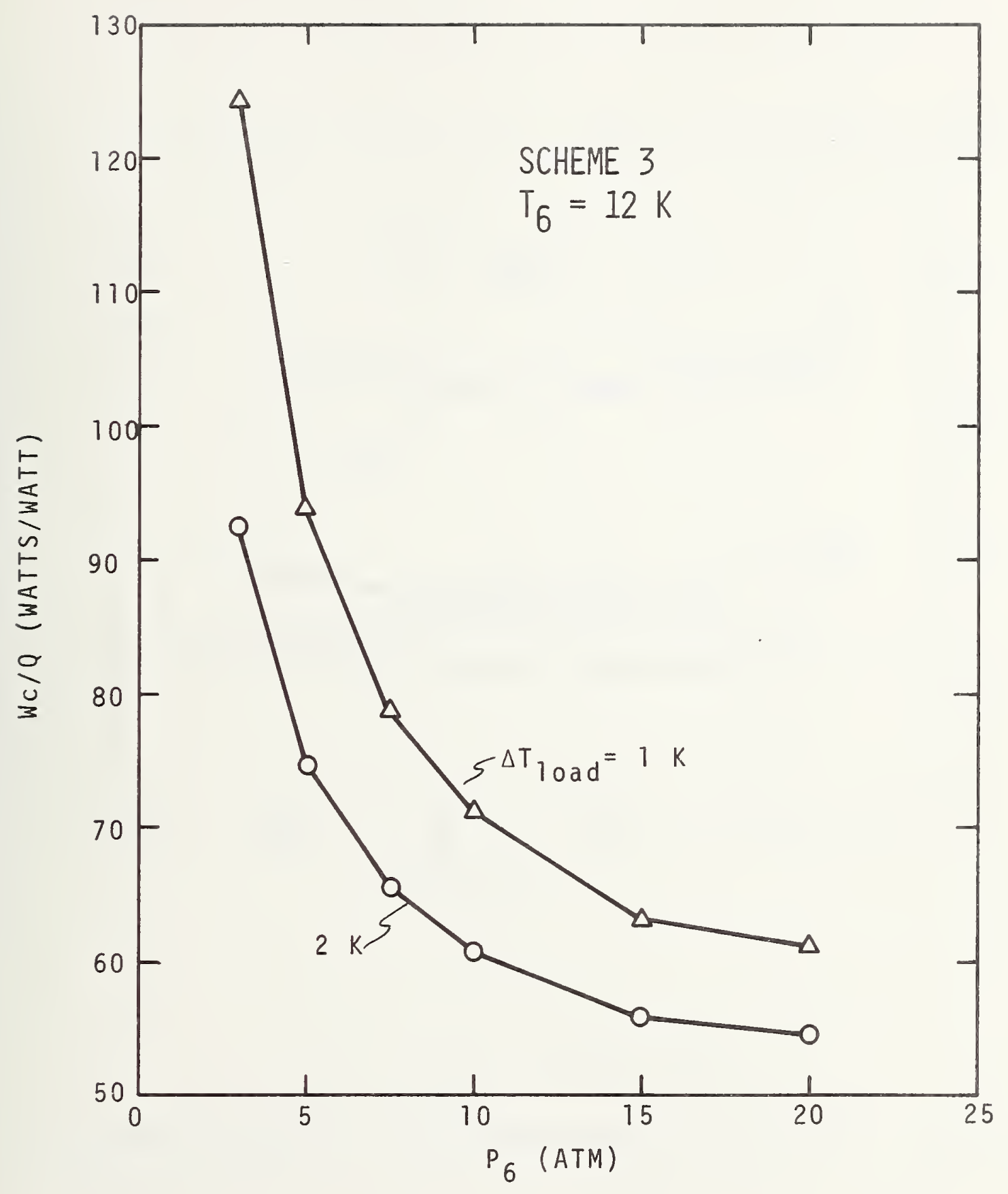

Figure 4.20 Scheme 3 performance for a $12 \mathrm{~K}$ load exit temperature. 


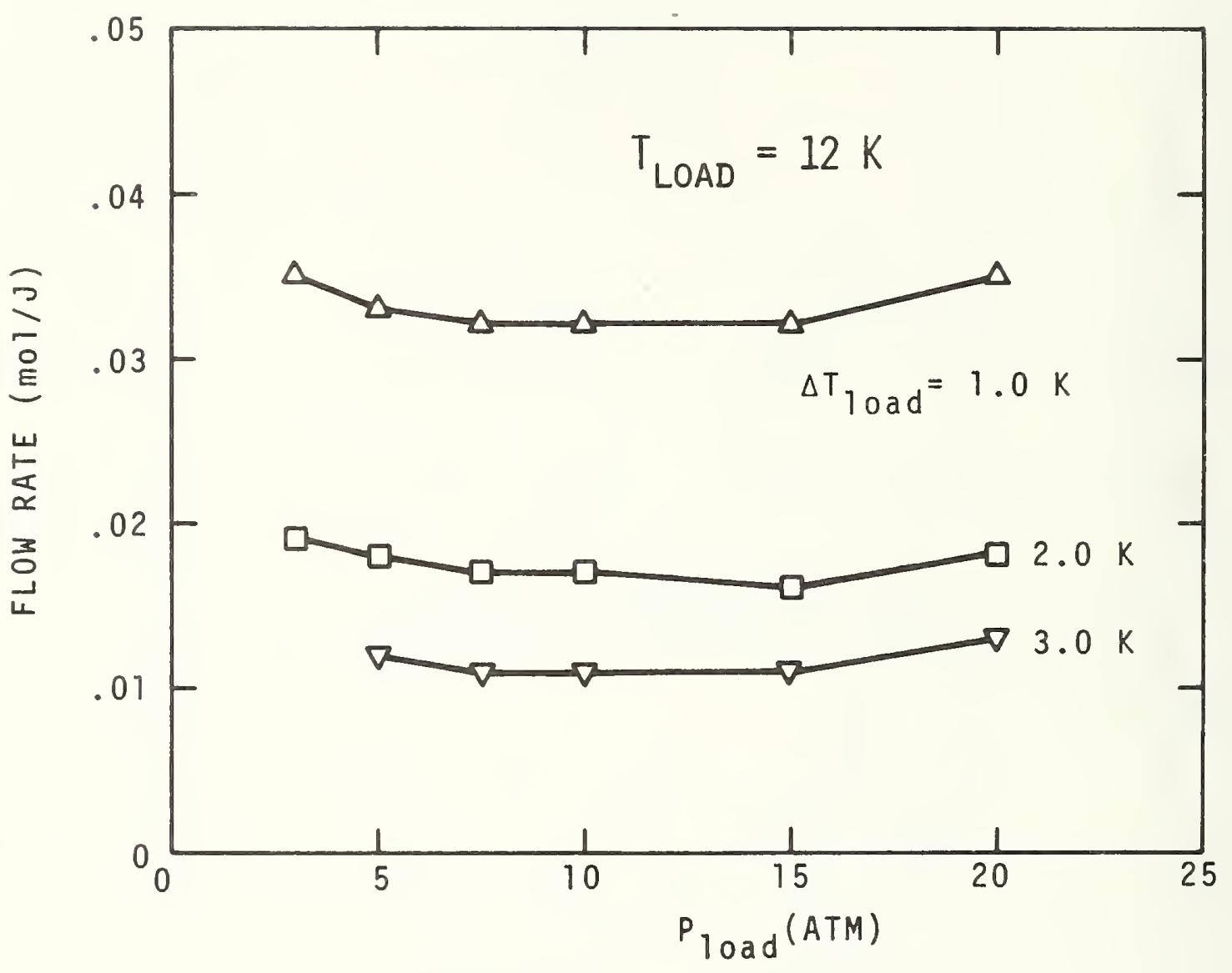

Figure 4.21 Flow rate vs. load pressure for a $12 \mathrm{~K}$ load exit temperature. 
$14 \mathrm{~K}$

LOAD EXIT TEMPERATURE 


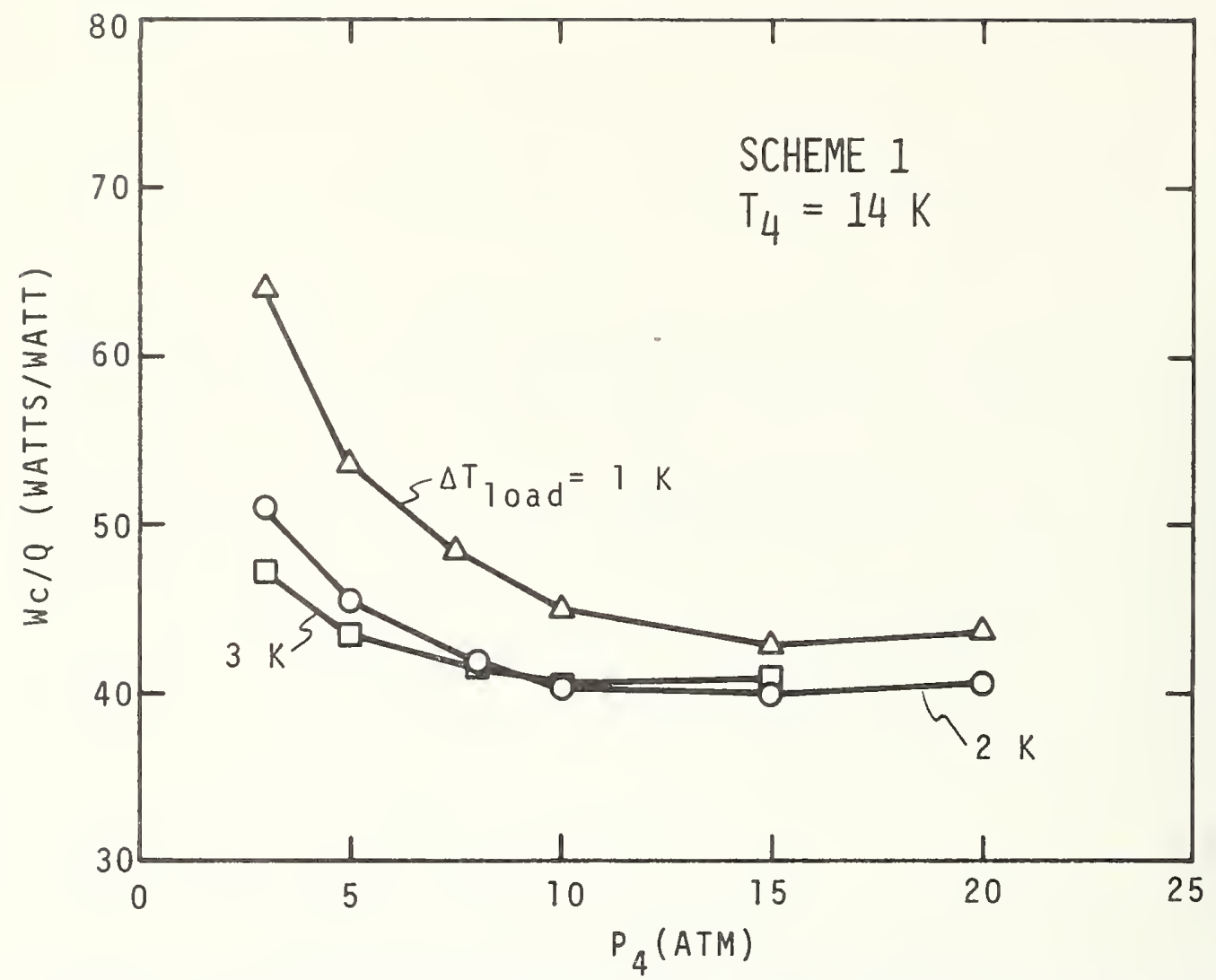

Figure 4.22 Scheme 1 performance for a $14 \mathrm{~K}$ load exit temperature.

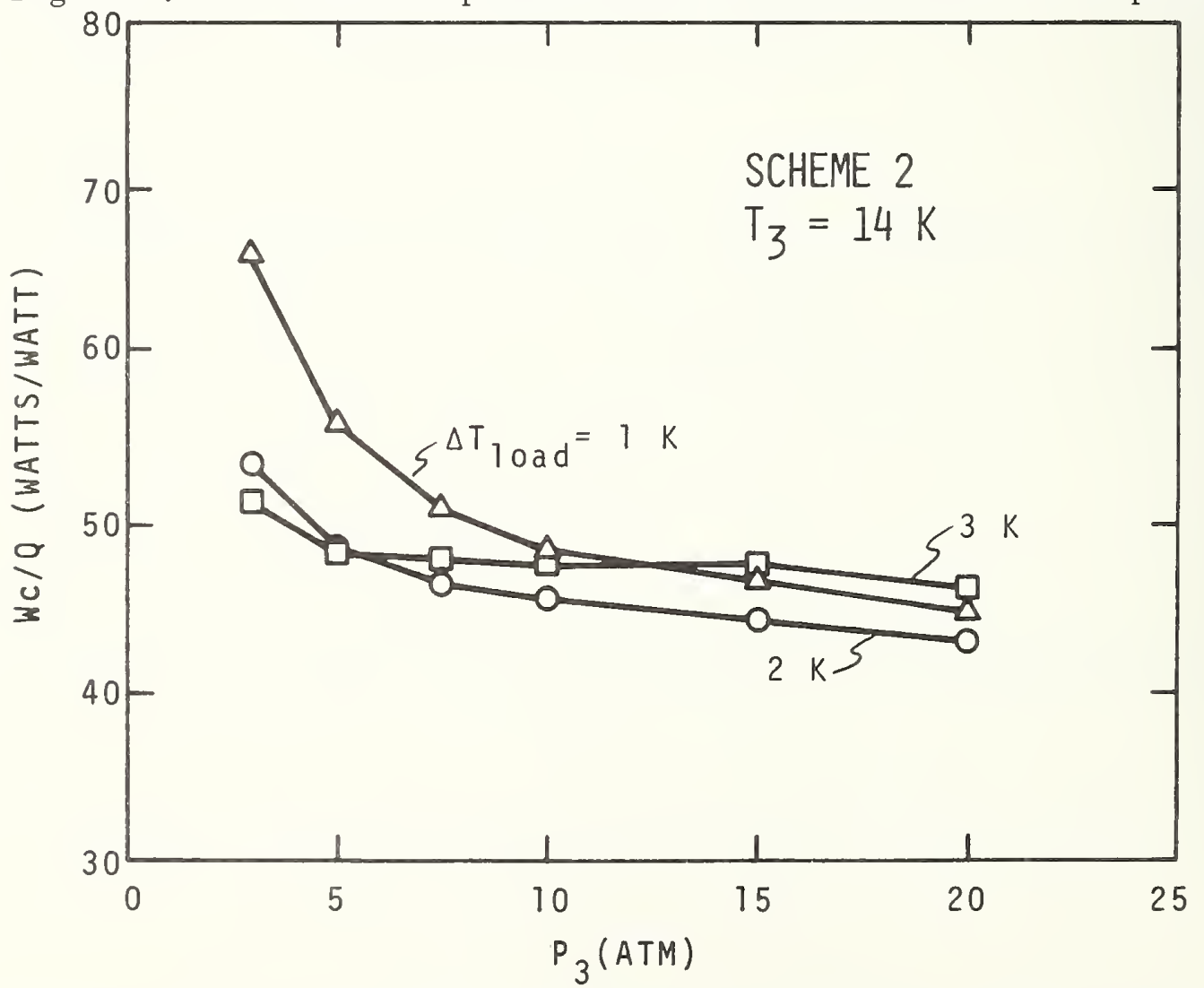

Figure 4.23 Scheme 2 performance for a $14 \mathrm{~K}$ load exit temperature. 


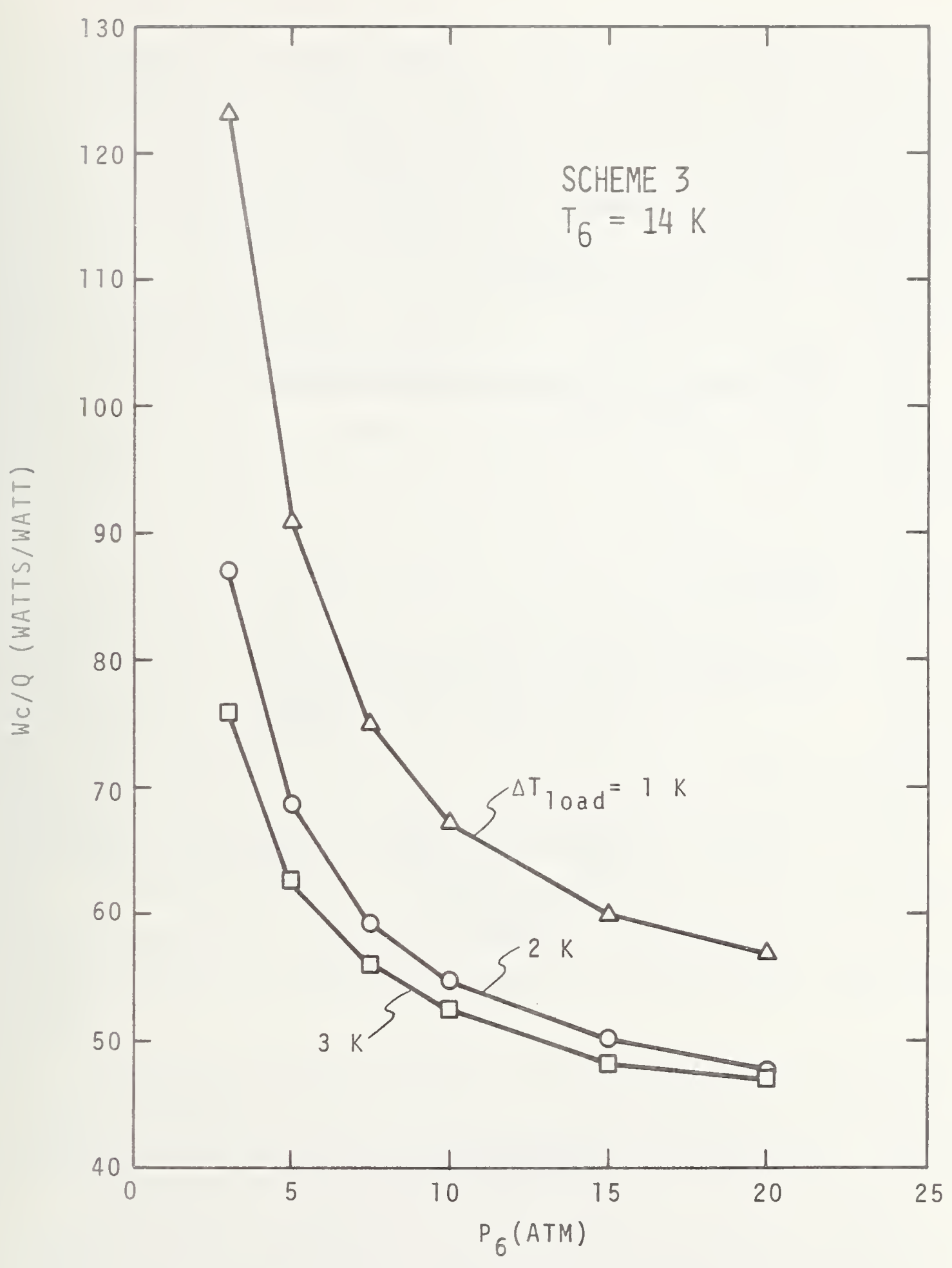

Figure 4.24 Scheme 3 performance for a $14 \mathrm{~K}$ load exit temperature. 


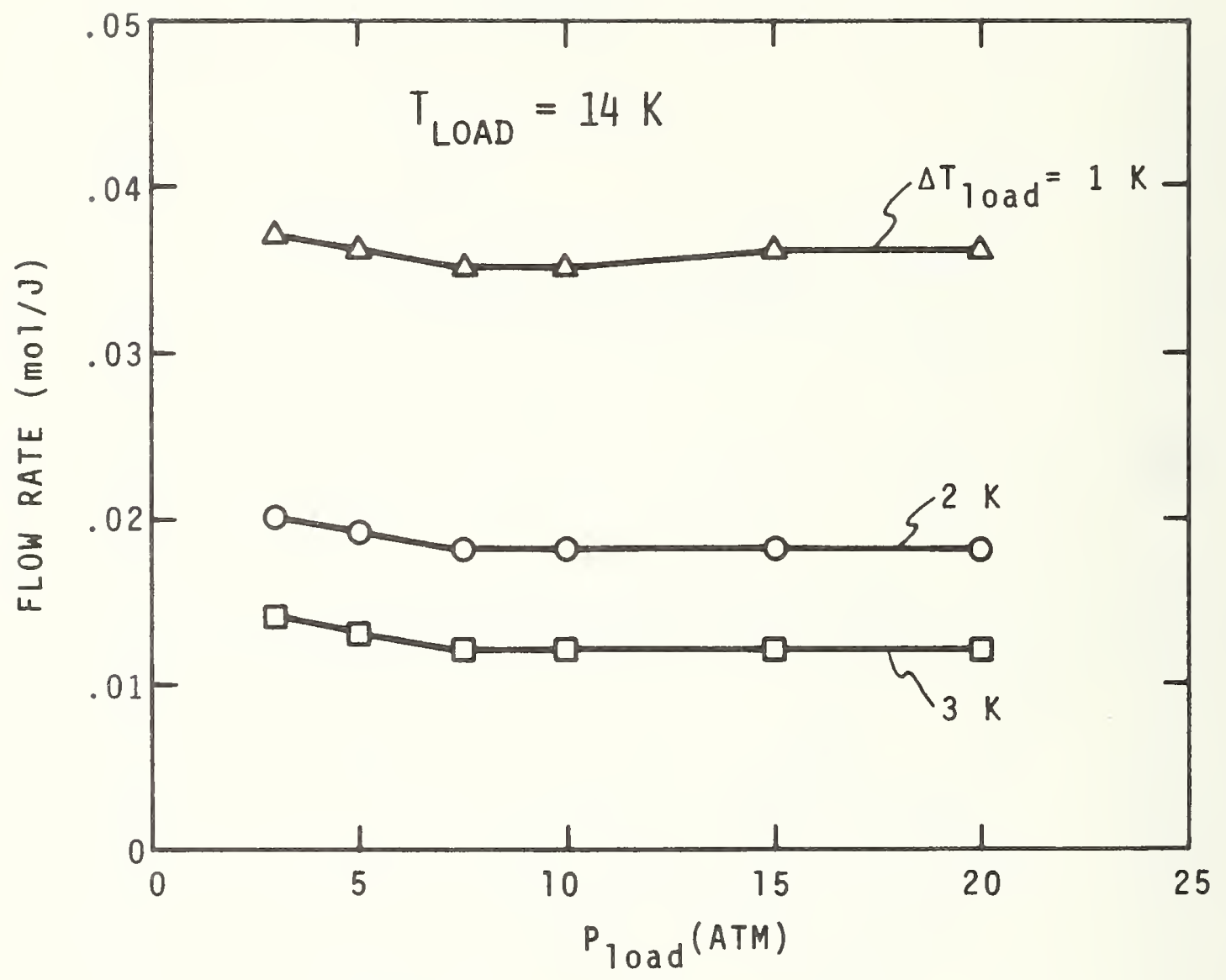

Figure 4.25 Flow rate vs. load pressure for a $14 \mathrm{~K}$ load exit temperature. 
is equivalent to an NTU of about 8. The effect of $A U / m^{\circ}$ on the refrigerator performance is shown in figures 4.8 and 4.16. Figure 4.16 shows there is little value in increasing the heat exchange $r$ size much beyond $1100 \mathrm{~J} / \mathrm{mol}-\mathrm{K}$, whereas substantial reductions in size below $1100 \mathrm{~J} / \mathrm{mol}-\mathrm{K}$ result in a significant increase in the compressor work. Although by no means a true optimum, $1100 \mathrm{~J} / \mathrm{mol}-\mathrm{K}$ appears to be a reasonable heat exchanger size for an efficient refrigerator.

The choice of $30 \mathrm{~K}$ for the temperature at the top end of the refrigerator heat exchanger was somewhat arbitrary. This temperature is sufficiently high that helium behaves nearly as an ideal gas, while at the same time, it is low enough that an excessively large heat exchanger is not required. In future studies, some attention should be given to optimizing this temperature. A simple approach such as that taken in section 3 will probably not be adequate, however, because of the nonideal behavior of helium at low temperatures.

An expander efficiency of 0.70 was chosen as being a value typical of a good, but not necessarily excellent expander. For large turboexpanders efficiencies in excess of 0.8 are possible [9].

The pump efficiency of 0.5 is taken as typical of a high quality centrifugal pump. One curve in figure 4.7 is presented for a pump efficiency of 0.9 , a value representative of a high quality reciprocating pump.

Most of the curves are for a transmission line pressure drop of $1 \mathrm{~atm}$, but figures 4.9,4.10, and 4.11 give results for 0,1 , and $2 \mathrm{~atm}$.

\section{DISCUSSION}

The complex shapes of the performance curves in section 4 result from the interaction of several effects. The more important ones are the work required to circulate the helium through the line, 
the temperature difference at the lower end of the heat exchanger, T2 - T4, and the Joule-Thoms on effect.

The pump work required to circulate the fluid through the transmission line causes the large $\mathrm{Wc} / Q$ at low pressures. Because this work is proportional to the specific volume of the helium, the high specific volumes associated with lower pressures result in large pumping losses. Figures 4.9,4.10, and 4.11 illustrate this effect for three load pressure drops.

For an adiabatic line, the minimum work required to circulate the fluid is

$$
\mathrm{W}_{\text {ideal }}=\mathrm{T}_{\mathrm{o}} \Delta \mathrm{S}
$$

The minimum work differs from the work input to a reversible low temperature pump, $T_{p} \Delta S$. And eq (8) shows that all reversible processes for circulating the helium require the same work input regardless of the temperature of the circulating pump. For example, a reversible low temperature pump requires less pump shaft work than an ambient temperature pump because of the increased density of the fluid, but this advantage is cancelled by the refrigerator work required to remove the pump work from the fluid. For a real pump operating at low temperature, the irreversibilities must also be removed by the refrigerator, and herein lies the disadvantage of the low temperature pump. Thus, the pump losses must be small compared to the load for this arrangement to be competitive.

This disadvantage is partially offset by the reduced compressibility, (and hence reduced pump work) of helium at low temperatures. As helium becomes less compressible at low temperature, the entropy change (at constant enthalpy) between two given pressures is reduced, and thus the ideal work required to circulate the helium is reduced. An ambient temperature pump cannot take advantage of this reduction in the ideal work because the concomitant imbalance in the specific heats makes perfect heat exchange impossible. 
The temperature difference at the lower end of the heat exchanger, $\mathrm{T} 2$ - T4, represents lost refrigeration. Because of the imbalance in the specific heats in the two sides of the heat exchanger, this temperature difference may become as large as $2 \mathrm{~K}$, resulting in substantial losses. The bump in the zero atmosphere $\Delta \mathrm{P}$ curve of figure 4.10 is primarily due to the variation of $\mathrm{T} 2-\mathrm{T} 4$ with pressure.

At high pressures, the Joule-Thoms on coefficient becomes negative and the cooling produced by the expander decreases for a given pressure ratio. For scheme 1 the truncation of the higher $\Delta \mathrm{T}$ curves at high pressure results from this effect. The expansion engine simply cannot produce the cooling required in the load.

A change in a single transmission line variable might appear simultaneously in several of the effects discussed above. For example, an increase in the pressure might result in decreased pump work, increased heat exchanger $\Delta T$, and an adverse Joule-Thomson effect. For this reason, it is necessary to make a complete cycle analysis, as has been done here, rather than rely on simplified models that may consider only one effect.

The results show that scheme 1 gives the lowest values of $\mathrm{Wc} / \mathrm{Q}$, but that its useful pressure range becomes more limited as the load temperature is reduced. An increasingly negative Joule-Thoms on coefficient with high pressure and low temperature is the cause of this difficulty.

Scheme 2 will always produce refrigeration, but not necessarily with pressures greater than atmospheric in the return side of the heat exchanger. Only solutions with return pressures of one atmosphere or greater are presented in section 4, and truncation of some of the curves on the low pressure side results. 
The work required for scheme 2 is significantly greater than for scheme 1. The primary reason is that the temperature level of the expansion engine is lowered by a value equal to the $\Delta T$ at the bottom of the heat exchanger. Because of the imbalance in the heat exchanger this $\Delta T$ can amount to as much as $2 \mathrm{~K}$, which causes a significant reduction in the cooling power of the expander.

Although scheme 3 might be expected to exhibit low efficiencies because of the low temperature pump, our results show that its Wc/Q is nearly identical to that of scheme 2 at $10 \mathrm{~K}$ and $12 \mathrm{~K}$. At $8 \mathrm{~K}$, scheme 3 has a significantly lower Wc/Q than scheme 2 over much of the pressure range investigated.

When we analyze the efficiency of a complete refrigerator, using eq (7), we find that scheme 1 can be expected to yield efficiencies (percent of Carnot) of about 25 percent and schemes 2 and 3 yield efficiencies of about 20 percent. These values are typical for about $10 \mathrm{~atm}$ and the refrigerator parameters listed in section 4. Because no attempt was made to optimize $\mathrm{T} l$ or $\Delta \mathrm{T}$ load, conclusions regarding the efficiency as a function of temperature should be made with care. 


\section{COST ESTIMATES}

A precise estimate of the cost of transmission line refrigeration would require a complete specification of a number of parameters such as the transmission line geometry, temperature, heat leak, and conductor losses. Because these parameters are not well defined at this time, we estimate the capital and operating costs of the refrigeration for a range of temperatures and line heat loads.

\section{1 Capital Costs}

The initial or capital cost of the refrigerators in dollars is estimated from the relationship [1]

$$
C_{i} \approx 6000(\mathrm{Wc} / \mathrm{e})^{0.7} \text {, }
$$

where Wc (kilowatts) is the isothermal compressor power calculated from the cycle analysis, and $e(\approx 0.6)$ is the efficiency of a real compressor compared to an ideal isothermal compressor.

Dividing eq (8) by the transmission line length, L, and factoring the right-hand side, we obtain the capital cost per unit length of transmission line in the form

$$
C_{i} / L=6000\left[\left(\frac{W c}{e Q}\right)\left(\frac{Q}{L}\right)\right]^{0.7}[L]^{-0.3} .
$$

Because the cycle analysis gives different values of $\mathrm{Wc} / \mathrm{Q}$ for different schemes and operating conditions, we choose the minimum Wc/Q obtained from the cycle analysis at each temperature. These minimum values of $\mathrm{Wc} / \mathrm{Q}$ are given in table 6.1 along with the corresponding Carnot efficiency. In all cases, the optimum was obtained using scheme 1. 


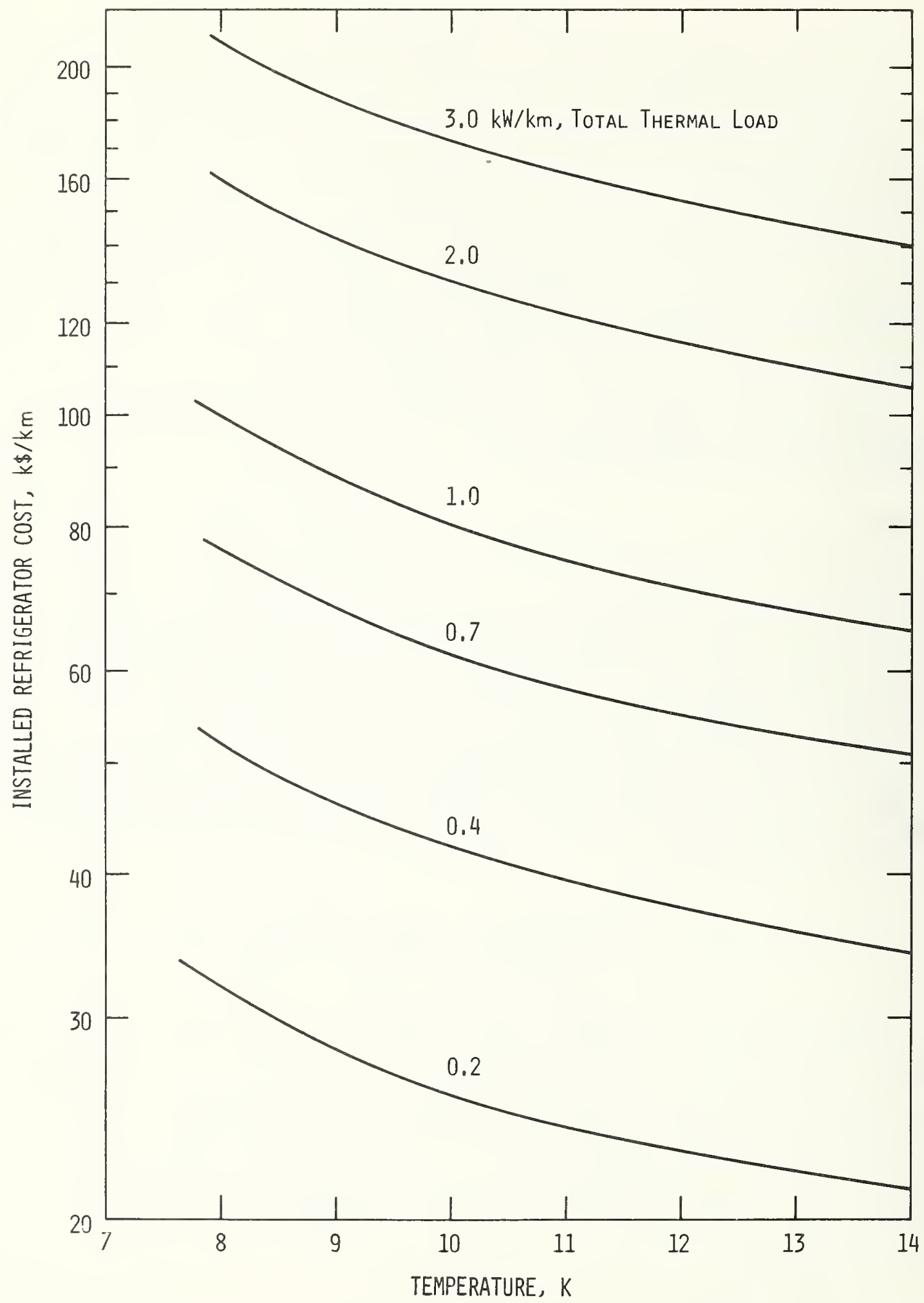

Figure 6.1 Minimum installed refrigerator cost $/ \mathrm{km}$ for a $10 \mathrm{~km}$ refrigerator spacing (excluding site and site development costs). 
Table 6. I Optimum refrigerator performance for $\mathrm{AU} / \stackrel{\circ}{\mathrm{m}}=1100$ and $\eta_{\mathrm{e}}=0.7$.

$\begin{array}{rcccc}\text { T(K) } & \text { Wc/Q } & (\text { Wc/Q) Carnot } & \text { Percent Carnot } & \text { Percent Carnot } .6 \\ 8 & 88 & 35.6 & 40.5 & 24.3 \\ 10 & 65 & 28.3 & 43.5 & 26.1 \\ 12 & 58 & 23.4 & 40.4 & 24.2 \\ 14 & 49 & 19.9 & 38.3 & 23.0\end{array}$

It is important to note that a variety of cycle parameters must be specified to obtain this minimum $W c / Q$. The optimization process is a highly nonlinear function of these various parameters, and it may be possible to improve (reduce) Wc/Q with subsequent work. But we feel that they are realistic for this study. The falloff in efficiency with increasing temperature is probably due to holding $\mathrm{Tl}$ constant at $30 \mathrm{~K}$. This decrease in efficiency should not be regarded as characteristic when the complete cycle is optimized.

The thermal load per unit length, Q/L, may be divided into (1) a temperature and current independent component, $Q_{f}$, which is the sum of dewar losses and dielectric losses, and (2) losses in the superconductor, $Q_{c}$. From previous studies reported by the Linde and the BNL groups, the fixed losses, $Q_{f}$, probably will be somewhere in the range 0.05 to 2. 0 kilowatts per kilometer of line, depending on a variety of design parameters. The superconductor losses may lie somewhere in the range 0.2 to 2.0 kilowatts per kilometer. Because of the emphasis on low-loss materials in the Stanford project, a reasonable range of the total losses to be considered here is 0.2 to $3 \mathrm{kw} / \mathrm{km}$ of line.

For an assumed refrigerator spacing of $10 \mathrm{~km}$, figure 6.1 gives the minimum installed refrigerator cost per $\mathrm{km}$ as a function of the temperature for various values of the total the rmal load (exclusive of coolant friction losses). For spacings different from $10 \mathrm{~km}$, or for refrigerator 
efficiencies different from those given in table 6.1, the cost should be adjusted according to the expression

$$
\frac{\left(C_{i} / L\right)^{\prime}}{\left(C_{i} / L\right)}=\left[\frac{(\text { refrigerator efficiency })}{\text { (refrigerator efficiency) }},\right]^{0.7}\left[\frac{L}{L^{\prime}}\right]^{0.3}
$$

A change in $L$ by a factor of 2 will change $C_{i}$ by only about $23 \%$, which is within the accuracy of these cost calculations. It should be noted at this point, that operation at the point of maximum refrige rator efficiency is not advocated. The thermal and electrical requirements of the line must naturally be considered, and the final selection of the operating conditions should take account of both the line and the refrigerator characte ristics.

\section{2 Optimum Refrigerator Spacing}

Optimizing the distance between refrigerators is a problem of great complexity, so we will only touch on it here. The true optimum spacing will result in lowest total cost (capital plus operating) for the line and the refrigerator over their expected life. Thus, the coolant passage flow area, which influences the line cost, line pressure drop, line heat leak, refrigerator size, etc., cannot necessarily be held constant in optimization calculations.

If we consider only the refrigerator capital costs, then an optimum spacing results because of the effect of spacing on the coolant pumping losses, and hence on the $W c / Q$ required.

The compressor work per unit of refrigeration, $W c / Q$, may be approximated for cost estimating purposes by

$$
W c / Q=(W c / Q)_{0}\left(1+\frac{W_{p}}{Q}\right),
$$

where the subscript o refers to zero pressure drop in the line and $\mathrm{W}$ is the pumping power required. It can be shown that

$$
\mathrm{W}_{\mathrm{p}} \underset{48}{\sim} \stackrel{\circ}{\mathrm{m}} \Delta \mathrm{P},
$$


and that

$$
\mathrm{L} \sim \stackrel{\circ}{\mathrm{m}} \text {, }
$$

since

$$
(\mathrm{Q} / \mathrm{L}) \mathrm{L}=\stackrel{\circ}{\mathrm{m}} \mathrm{C}_{\mathrm{p}} \Delta \mathrm{T} \text { line }
$$

Thus,

$$
\mathrm{W}_{\mathrm{p}} \sim \mathrm{L} \Delta \mathrm{P}
$$

and eq (10) may be rewritten as

$$
W_{c} / Q=(W c / Q)_{0}(1+\alpha L \Delta P),
$$

or as

$$
W c / Q=(W c / Q)_{0}\left(1+\beta L^{n}\right) .
$$

The value of the exponent $n$ implies the following about the coolant passage pressure drop and cross sectional area.

1. If $\mathrm{n}=1, \Delta \mathrm{P} / \mathrm{L} \sim 1 / \mathrm{L}$ and large increases in the area are required as the length increases.

2. If $n=2, \Delta P / L=$ constant and moderate increases in the area are required as the length increases, because $m \sim L$.

3. If $\mathrm{n}=4$, the area is nearly constant for turbulent flow in the line.

A reasonable value of $\mathrm{n}$ would seem to lie between 2 and 3 .

Combining eqs (9) and (11), we obtain

$$
C_{i} / L=6000\left[\left(\frac{W c}{e Q}\right)_{0}\left(\frac{Q}{L}\right)\left(1+\beta L^{n}\right)\right]^{0.7}[L]^{-03}
$$


When reasonable values for $\beta$ and $n$ are chosen, we find that eq (10) gives an optimum refrigerator spacing on the order of $100 \mathrm{~km}$. This compares favorably with $80 \mathrm{~km}$ predicted by Cairns, Swift, Edney and Steel [10].

If we consider the total cost (including operating costs) of the line during its life, then some of these costs, such as power costs, will be proportional to the first power of installed compressor power, and we may write

$$
C_{T} / L \sim \frac{\left(1+\beta L^{n}\right)^{0.7}}{(L)^{0.3}}+A\left(I+\beta L^{n}\right)
$$

where $C_{T}$ is the total cost of the refrigeration. When $A$ is of the order of 1 (i. e., the power costs equal the capital costs over the life of the line) the optimum spacing is reduced to about $10 \mathrm{~km}$, which is in agreement with the length used in section 6. I. In a precise analysis the constant A should be weighted so as to take account of the diminished present worth of future dollars. This consideration would tend to increase the line length.

Labor and supervisory costs per refrigerator are relatively independent of the refrigerator size, so that their cost per unit length of line is proportional to $1 / \mathrm{L}$. Consideration of these costs increase the optimum length over the $10 \mathrm{~km}$ of the previous example.

Clearly, refrigerator spacing is a problem which will require considerable study. We have touched on the problem here to demonstrate the complexity of the problem and to provide a rough estimate for the cost analysis.

\section{3 Operating Costs}

The estimated annual operating cost of refrigerating the line is obtained by dividing the cost per refrigerator by the length of line 


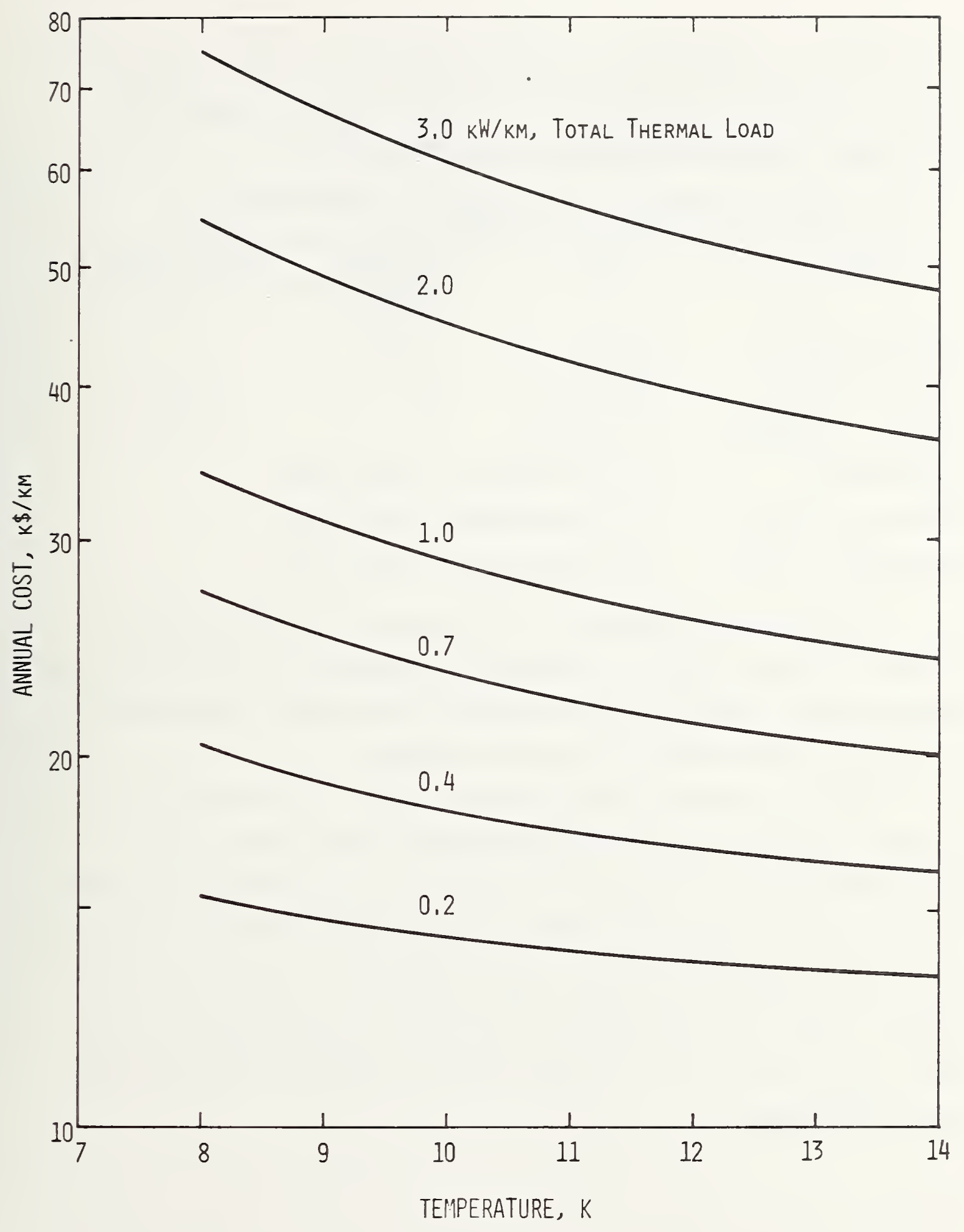

Figure 6.2 Annual refrigerator cost based on table 6.2. 
serviced by the refrigerator. Table 6.2 gives the assumed operating costs per refrigerator which were used to construct the curves of operating cost per kilometer given in figure 6.2.

Table 6.2 Assumed operating cost per refrigerator.

Item

Electric Power

Labor - direct

Labor - overhead

Maintenance

Taxes, insurance

Supervision, misc.
Unit

$\mathrm{kW}-\mathrm{hr}$

man-hr

$50 \%$ direct

$6 \%$ of installed cost per year

$3 \%$ of installed cost per year

$\$ 20,000$ per year, all cases.
Unit Cost Yearly Cost

$$
\text { (\$/unit) }
$$

.012

6. 0

52,600

23,300

The estimates in table 6.2 are analogous to those made by Winters and Snow [1]] in an economic analysis of a $1.5 \mathrm{~kW}$ helium refrigerator. These estimates should be considered as approximations, not as the results of a detailed analysis.

The low sensitivity of the curves in figure 6.2 to temperature and thermal load results from the high fixed costs (Labor and Supervision) per $\mathrm{kW}$. Larger refrigerator spacings would reduce the relative size of these fixed costs, and consequently increase the sensitivity of the total annual cost to temperature and thermal load. In a similar fashion, highly reliable refrigerators requiring an operator only 8 hours a day, instead of the 24 hours assumed, would yield the same advantages. 


\section{ACKNOWLEDGMENTS}

The author wishes to thank V. D. Arp for a number of suggestions and helpful discussions concerning all aspects of this work. W. R. Parrish was always able to find time for my questions on programming and numerical analysis. Both of these contributions are gratefully acknowledged. 


\section{NOMENCLATURE}

A

$\mathrm{C}_{\mathrm{i}}$

C

e

$\mathrm{H}$

L

$\stackrel{\circ}{\mathrm{m}}$

NTU

P

$q$

Q

$\mathrm{R}$

S

$\mathrm{T}$

U

Wc

Greek

$€$

$\eta_{\mathrm{C}}$

$\eta_{\mathrm{e}}$

$\eta_{\mathrm{p}}$

heat transfer surface area on one side of heat exchanger installed cost of refrigerator, \$

specific heat at constant pressure

isothermal compressor efficiency

specific enthalpy

refrigerator spacing, $\mathrm{km}$

mass flow rate

number of heat exchanger transfer units, $\mathrm{AU} / \stackrel{\mathrm{m}}{\mathrm{m}}_{\mathrm{p}}$

pressure

heat transfer rate, watts

thermal load in the transmission line, watts

gas constant

entropy

absolute temperature

overall heat transfer coefficient

ideal work of compression

heat exchanger effectiveness

Carnot work/actual work for a refrigerator with given heat load expansion engine efficiency, actual work/isentropic work pump efficiency, isentropic work/actual work dimensionless heat exchanger length 
Subsc ripts

c cold side of heat exchanger

h warm side of heat exchanger

$\circ \quad$ ambient conditions

p pump 


\section{REFERENCES}

1. Strobridge, T. R., IEEE Transactions on Nuclear Science, NS-16, No. 3 (1969).

2. Strobridge, T. R., Cryogenic Refrigerators - an Updated Survey, Nat. Bur. Stand. (U.S.) Tech. Note 655, 11 pages (1974).

3. Rohsenow, W. M., and Choi, H. Y., Heat, Mass, and

Momentum Transfer, p. 314 (Prentice-Hall, Englewood Cliffs, New Jersey, 1961).

4. McCarty, R. D. , Thermophysical properties of helium-4 from

2 to $1500 \mathrm{~K}$ with pressures to 1000 atmospheres, Nat. Bur.

Stand. (U.S.), Tech. Note 631 (1972).

5. McCarty, R. D. , Thermophysical properties of helium from

2 to $1500 \mathrm{~K}$ at pressures to $1 \times 10^{8}$ pascals, to be published (1973).

6. Arp, V. D., Refrigeration of superconducting rotating machinery,

Nat. Bur. Stand. (U. S. ), NBSIR 73-331 (1973).

7. Grassmann, P., and Kopp, J., Kaltetechnik 9, 306 (1957).

8. Kapitza, P. L., and Danilov, I. B., Cryogenic engineering present status and future development, Proceedings of the First International Cryogenic Engineering Conference, Tokyo, Japan, 1967, p 228 (Heywood-Temple Industrial Publications, 1968).

9. Linhardt, H. D., LNG/Cryogenics, 7 (February/March 1973). 10. Cairns, D. N. H. , Swift, D. A., Edney, K., and Steel, A. J., Low temperatures and electric power, Proc. International Institute of Refrigeration, London, p. 155 (1969).

11. Winters, A. R., and Snow, W. A., Advances in Cryogenic Engineering 11 , p. 111 (Plenum Press, New York, N. Y., 1966). 


\begin{tabular}{|c|c|c|c|}
\hline $\begin{array}{l}\text { U.S. DEPT. OF COMM. } \\
\text { BIBLIOGRAPHIC DATA } \\
\text { SHEET }\end{array}$ & $\begin{array}{l}\text { 1. PUBLICATION OR REPORT NO. } \\
\text { NBSIR } 74-375\end{array}$ & $\begin{array}{l}\text { 2. Gov't Accession } \\
\text { No. }\end{array}$ & 3. Recipient's Accession No. \\
\hline \multirow{2}{*}{\multicolumn{3}{|c|}{$\begin{array}{l}\text { 4. TITLE AND SUBTITLE } \\
\text { REFRIGERATION FOR AN } 8 \mathrm{~K} \text { TO } 14 \mathrm{~K} \text { SUPERCONDUCTING } \\
\text { TRANSMISSION LINE }\end{array}$}} & $\begin{array}{l}\text { 5. Publication Date } \\
\text { October } 1974\end{array}$ \\
\hline & & & 6. Performing Organization Code \\
\hline \multicolumn{3}{|l|}{$\begin{array}{l}\text { 7. AUTHOR(S) } \\
\text { David E. Daney }\end{array}$} & 8. Performing Organ. Report No. \\
\hline \multicolumn{3}{|c|}{$\begin{array}{l}\text { 9. PERFORMING ORGANIZATION NAME AND ADDRESS } \\
\text { NATIONAL BUREAU OF STANDARDS, Boulder Labs } \\
\text { DEPARTMENT OF COMMERCE }\end{array}$} & $\begin{array}{l}\text { 10. Project/Task/Work Unit No. } \\
2750575 \\
\text { PR } 1745\end{array}$ \\
\hline \multicolumn{3}{|c|}{$\begin{array}{l}\text { 12. Sponsoring Organization Name and Complete Address (Street, City, State, ZIP) } \\
\text { Stanford University } \\
820 \text { Quarry Road } \\
\text { Palo Alto, California } 94304\end{array}$} & $\begin{array}{l}\text { 13. Type of Report \& Period } \\
\text { Covered }\end{array}$ \\
\hline
\end{tabular}

15. SUPPLEMENTARY NOTES

16. ABSTRACT (A 200-word or less factual summary of most significant information. If document includes a significant bibliography or literature survey, mention it here.)

The performance of three supercritical refrigeration cycles for cooling superconducting transmission lines has been investigated for the temperature range of $8 \mathrm{~K}$ to $14 \mathrm{~K}$. This temperature range is applicable to the Stanford superconducting $\left(\mathrm{Nb}_{3} \mathrm{Sn}\right)$ line. These cycles, which were selected as being the most practical, are the Brayton cycle with the expander before the load, the Brayton cycle with the expander after the load, and the Brayton cycle with a separate supercritical helium loop and circulating pump.

The results are presented as curves of Wc/Q (ratio of the work of compression to the refrigeration load) vs the transmission line exit pressure for various transmission line pressure and temperature drops. Contrary to popular belief, all three cycles are competitive. Maximum efficiencies (percent of Carnot) are about 25 percent.

Estimated capital and operating costs are presented as a function of transmission line temperature for several values of thermal load per length of line.

17. KEY WORDS (six to twelve entries; alphabetical order; capitalize only the first letter of the first key word unless a proper name; separated by semicolons)

Brayton cycle; refrigeration; superconducting transmission lines; superconductors.

18. AVAILABILITY

$\sqrt{x}$ Unlimited

For Official Distribution. Do Not Release to NTIS

Order From Sup. of Doc., U.S. Government Printing Office

Wa shington, D.C. 20402, SD Cat. No.C13

$\square$ Order From National Technical Information Service (NTIS) Springfield, Virginia 22151

\begin{tabular}{|l|l|}
\hline $\begin{array}{l}\text { 19. SECURITY CLASS } \\
\text { (THIS REPURT) }\end{array}$ & 21. NO. OF PAGES \\
UNCLASSIF IED & 22. Price \\
\hline $\begin{array}{l}\text { 20. SECURITY CLASS } \\
\text { (THIS PAGE) } \\
\text { UNCLASSIFIED }\end{array}$ & \\
\hline
\end{tabular}




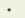

